\title{
RAZÃo DE PERDAS DE SOLO SOB CULTIVO DE TRES LEGUMINOSAS
}

\author{
PAULO CESAR DO NASCIMENTO \\ Engenheiro Agrônomo
}

Orientador: DR. FRANCISCO LOMBARDI NETO

Dissertação apresentada à Escola Superior de Agricultura "Luiz de Queiroz", da Universidade de São Paulo, para obtenção do título de Mestre em Agronomia, Area de Concentração: Solos e Nutrição de Plantas.

\author{
PIRACI CABA \\ ESTADO DE SÃO PAULO - BRASIL \\ Setembro - 1994
}


Ficha catalografica preparada pela seça de Livros da Divisao de Eiblioteca e Documentaçăo - FCLe/UGF

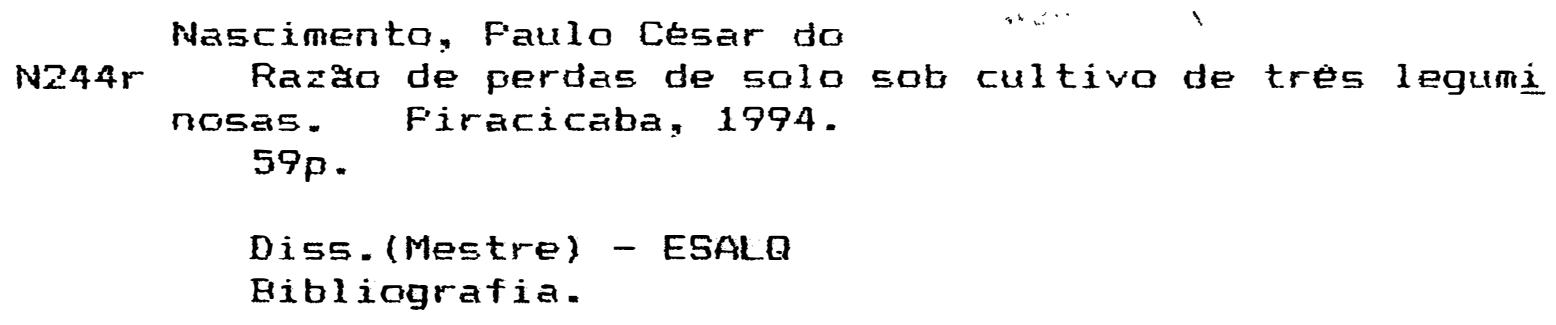

1. Leguminasa comot adubo $Z$. Leguminosa camo cobertu ra 3. Solo - Conservaça 4.,5olp Mangejo 5.5010 - E rosado - Controle I. Escolà Superior de Agricultura Luiz de Queiroz, Firacicaba

CDD $\quad 631.45$ 


\section{RAZÃo dE PERDAS DE SOLO SOB CULTIVO DE TRES LEGUMINOSAS}

PAUlo cesar do nAscimento

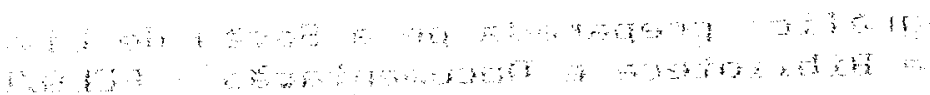

Aprovada em: $11 / 11 / 1994$

Comissão Julgadora:

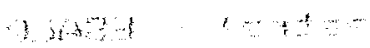

Dr. FRANCISCO LOMBARDI NETO SCS/IAC Prof. Dr. VICENTE DE PAULA PEREIRA PCAV/UNESP Prof. Dr. OTAVIO FREIRE IPEA/UNESP

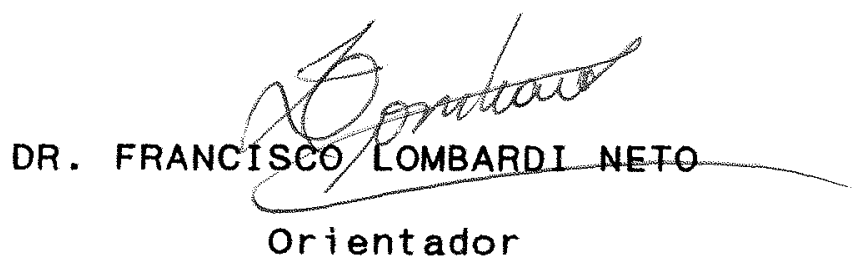


Aos meus pais, Laerte César e Clarice, e meus irmãos, Laerte e Ligia, pelo apoio e incentivo a minha formação, DEDICO

\author{
A Beatriz, \\ OFERECO
}




\section{AGRADECIMENTOS}

Ao Dr. Francisco Lombardi Neto, Pesquisador Cientifico da seção de conservacão do solo do Instituto Agronómico de Campinas, pela orientação e apoio em todos os momentos;

A todos os pesquisadores e funcionários da seção de Conservação do Solo do Instituto Agronômico de Campinas, pela amizade e apoio expressos no dia-a-dia;

A Fundação de Amparo a Pesquisa do Estado de São Paulo, pela concessão de bolsa de estudo durante o curso;

Ao Engenheiro Agricola Flávio de Oliveira Cunha Sarvasi, pela amizade e incentivo nos trabalhos de campo;

A Silvana Cristina Teixeira, pela dedicaça na digitação do trabalho;

A todos os colegas da Escola Superior de Agricultura "Luiz de Queiroz", com os quais convivi e aprendi durante o curso; 
"Do rio que tudo arrasta

se diz violento,

Mas não se dizem violentas

as margens que o oprimem".

\section{B. BRECHT}

"Gente é para brilhar, e não para morrer de fome" 
SUMARIO

LISTA DE FIGURAS . . . . . . . . . . . . . . . . . . viii LISTA DE TABELAS . . . . . . . . . . . . . . . . . . . ix RESUMO . . . . . . . . . . . . . . . . . . . . $x$ SUMMARY .................... . . xi

1. INTRODUÇÃo . . . . . . . . . . . . . . . . . . . 1

2. REVISÃo BIBLIOGRAfICA . . . . . . . . . . . . . . . 4

2.1. Erosão: Fatores . . . . . . . . . . . . . 4

2.2. Estimativa das perdas por erosão . . . . . . 5

2.3. O fator C: importância e subfatores determinantes . . . . . . . . . . . . . . . 6

2.4. Efeitos da cobertura do solo........ 9

2.5. Leguminosas na conservação do solo . . . . . 14

3. MATERIAL E METODO . . . . . . . . . . . . 19

3.1. MATERIAL . . . . . . . . . . . . . . . . . 19

3.1.1. Caracterizạão do local . . . . . . . . 19

3.2. METODO . . . . . . . . . . . . . . . 23

3.2.1. Avaliação do desenvolvimento da crotalaria juncea L. . . . . . . . . . . . . . . . 23

3.2.2. Avaliação da Razão de Perdas de Solo para três leguminosas . . . . . . . . . . . . 23

3.2.3. Coleta de dados . . . . . . . . . . . . 25

3.2.3.1.Perdas de solo... . . . . . . . . . 25

3.2.3.2. Cobertura do solo . . . . . . . . . . 26

3.2.3.3.Altura das plantas........... . . 28

3.2.3.4.Produção . . . . . . . . . . . . . . . . 29

3.2.4. Análise dos dados........... 29 
4. Resultados e discussão . . . . . . . . . . . . . . . . 30

4.1. Avaliação do desenvolvimento da Crotalaria juncea... . . . . . . . . . . . . . 30

4.2. Avaliação da razão de perdas de solo para três leguminosas . . . . . . . . . . . . . . 38

5. CONClUSÖES . . . . . . . . . . . . . . . . . . . . 50

REFERENCIAS BIBLIOGRAFICAS . . . . . . . . . . . . . 52 
viii

\section{LISTA DE FIGURAS}

Figura

Página

1. Mapa mostrando a localização do município de

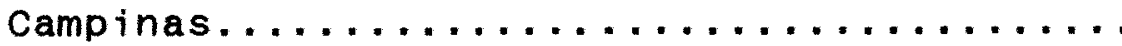

2. Balanço hídrico decendial para Campinas, $S P$ no ano agrícola 1990/91...............

3. Esquema de movimentação da Armação de Visadas Localizadas para avaliação da cobertura vegetal da Crotalaria juncea L...........

4. Variação da altura da planta em função do tempo para a Crotalaria juncea L..........

5. Variação da cobertura do solo em função do tempo para a crotalaria juncea L.........

6. Variação da cobertura do solo em função da altura da planta para a Crotalaria juncea L.

7. Variaçăo das perdas de solo acumuladas em função do tempo, para a Crotalaria juncea L.

8. Perdas de solo acumuladas em função da altura para a crotalaria juncea L............

9. Razão de perdas de solo para três leguminosas, em quatro estádios do ciclo das

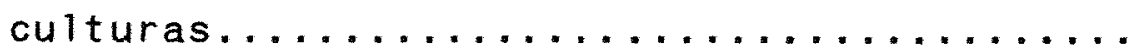

10. Razão de perdas de solo para três leguminosas............................... 


\section{LISTA DE TABELAS}

Tabela

Página

1. Características do horizonte superficial $(0-20 \mathrm{~cm})$ do latossolo roxo distrófico,

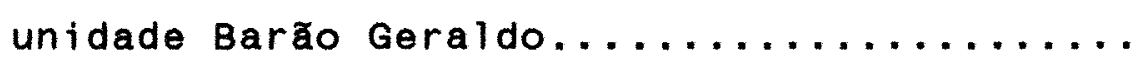

2. Seqüência de operações de instalação de culturas, no período $1973 / 79 \ldots \ldots \ldots \ldots \ldots$

3. Avaliação da altura de plantas, cobertura vegetal, perdas de solo e precipitação pluviométrica acumulada para o periodo de estudo da Crotalaria juncea.............

4. Perdas de solo para três leguminosas e solo descoberto, em quatro estádios da cultura.

5. Perdas de solo para três leguminosas e solo descoberto, em quatro períodos da cultura,

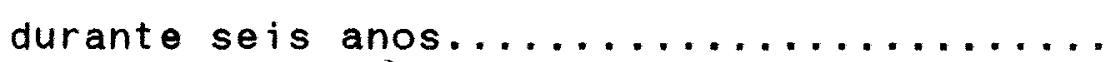




\title{
RAZÃo de PERDAS dE SOLO SOB CULTIVO DE TRES LEGUMINOSAS
}

\author{
Autor: PAULO CESAR DO NASCIMENTO \\ Orientador: DR. FRANCISCO LOMBARDI NETO
}

RESUMO

Com o objetivo de quantificar a protecăo do solo contra a erosáo oferecida por tres leguminosas utilizadas como adubo verde, foram analisados dados referentios a experimento de perdas de solo e água por erosáo conduzido pela segăo de Conservaçăo do Solo do Instituto Agronómico, no Centro Experimental de Campinas, durante seis anos agrfcolas $(1973 / 74$ a $1978 / 79)$. As leguminosas estudadas foram a Crotalaria juncea L. (crotalaria); stizolobium aterrinum Piper et Tracy (múcuña-preta) e Dolichos lablab L. ( $1 \mathrm{abelabe)}$.

Para a determinação dos estádios do ciclo das culturas com vista ao cálculo da razão de perdas de solo (RPS), foi instalada em quat ro talhoes coletores situados no mesmo local, no ano agricola 1990/91, a cultura da crotalaria juncea L. A evoluçăo desta leguminosa em relaça a aspectos como cobertura do solo e altura de plantas permitiu a divisăo do ciclo em estádios de $0-30^{-}, 30-60,60-90$ e $60-120$ dias apos. 
a semeadura $\theta$ ainda em perfodos de $0-30,0-60,0-90$ e $0-120$ dias após a semeadura, considerando-se a possibilidade de adoçảo de apenas um estádio para os adubos verdes.

Os resultados obtidos mostraram a mator protecăo oferecida pela mucuna-preta a erosão, com valores de RPS de 0,$28 ; 0,37 ; 0,17$ e,09 para os estádios de 0-30;30-60;6090 e 60-120 dias após semeadura. o labelabe apresentou, para os mesmos estádios; valores de 0,$50 ; 0,45 ; 0,27$ e 0,19 ; enquanto para a crotalária foram 0,$30 ; 0,42 ; 0,2600,24$.

Os resultados mostram uma protecão mais efetiva a partir dos 60 dias após a semeadura, por parte das especies avaliadas. A mucuna-preta teve uma maior efetividade na proteçăo do solo, seguida da crotalária no infcio do ciclo, - do labelabe, no estádio mais próximo ao florescimento. Esses dados das leguminosas mostraram estreita relaçăo com aspectos como a velocidade de desenvolvimento e caracteristicas morfologicas das plantas. 


\section{SOIL LOSS RATIO FOR THREE GREEN MANURES}

Author: PAULO CESAR DO NASCIMENTO Adviser: DR. FRANCISCO LOMBARDI NETO

\section{SUMMARY}

A field experiment of soil and water losses by erosion was carried out during six consecutive agricultural years $(1973 / 74$ to $1978 / 79)$ at the Experimental Center of Campinas, of the Instituto Agronómico, state of são Paulo, Brazil, (Typic Harplorthox) to evaluate the soil loss ratio to calculate the $c$ factor of the Universal Soil Loss Equation (USLE) for three green manure. The green manures studied were: Crotalaria juncea L., stizolobium aterrinum Piper et Tracy and Dolichos láblab L.

In order to establish the cropstage period, Crotalaria juncea L. was planted in four field plots of soil and water losses by erosion, during the agricultural year of $1990 / 91$, at the same location. The cropstage period was defined so that cover and height of crotalaria may be considered uniform, for the soil loss. Four cropstage periods were defined, for the vegetative cycle of crotalaria: $0-30,30-60,60-90$, and 60-120 days after planting, and an only one cropstage period was also defined: $0-30,0-60,0-90$ 
or $0-120$ days after planting.

The results showed that stizolobium aterrinum gave the best cover protection against soil loss, with values of soil loss ratio (SLR) of $0.28,0.37,0.17$ and 0.19 for the cropstage periods of $0-30,30-60,60-90$ and $60-120$ days after planting, respectively. Dolichos lablab showed values of SLR of $0.50,0.45,0.27$ and 0.19 and Crotalaria juncea showed values of $0.30,0.42,0.26$ and 0.24 for the same cropstage periods respectively.

The results also showed, that the cover protection from the three green manure were more effective after 60 days of planting. Stizolobium was the most efficient cover, following by crotalaria, mainly in the first cropstage period and Dolichos, during the flowering. This behavior had a fair relationship with aspects as velocity of development and morphological characteristics of plants. 
1.

\section{INTRODUÇAO}

As perdas de água e solo por erosão tem sido, por muito tempo, objeto de estudos por parte de pesquisadores de todo o mundo. Esses estudos, para a melhor compreensão do fenómeno, investigam aspectos de larga abrangência, referentes aos agentes causadores da erosão, como a chuva e - vento; as características do solo que o tornam mais ou menos susceptível, assim como a influência do homem.

os resultados mais recentes de pesquisas sobre esse tema, apontam para a importancia desse último aspecto. Assim, para uma determinada região, com condições homogêneas no que diz respeito à distribuição de chuvas $\theta$ sua erosividade, tem-se observado que solos naturalmente susceptiveis a erosão podem apresentar perdas abaixo dos niveis máximos de tolerância, quando mantidos sob vegetação natural ou utilizados de modo sustentável, enquanto solos com menor erodibilidade, expostos ao desmatamento, uso intensivo e atuação dos agentes erosivos, apresentam após alguns anos, grandes perdas e degradação em suas propriedades originais. A partir dessa constatação, tem-se procurado compatibilizar 
- uso agrícola do solo com a sua conservação e manutenção de características físicas e químicas favoráveis, evitando a sua degradação e possibilitando um bom potencial produtivo ao longo dos anos, através do uso e manejo adequado e execução de práticas conservacionistas nas áreas utilizadas.

Com esse objetivo, algumas alternativas tem sido desenvolvidas, no que diz respeito ao uso e manejo do solo. Medidas como um preparo do solo que evite sua excessiva pulverização mantendo suas caracteristicas fisicas favoráveis, a manutenção da cobertura do solo funcionando como proteção contra a ação da chuva; a prática de adubação verde, visando o suprimento de matéria orgânica, e conseqüentemente a maior estabilidade da agregação, tem uma eficácia já reconhecida, com uma aplicaça cada vez mais difundida. Várias espécies de plantas tem sido utilizadas para essas práticas com resultados satisfatórios.

Nesse contexto, a utilização das leguminosas na conservação do solo, apresenta um potencial ainda não totalmente conhecido e explorado. A melhoria das condições físicas e químicas do solo proporcionada por essas espécies, tem sido aproveitada para seu uso como adubação verde e adubação orgânica, ao mesmo tempo em que o manejo dos restos de culturas tem sido objeto de estudos.

Entre os aspectos favoráveis do uso de espécies de leguminosas, no entanto, a sua capacidade de proteção direta do solo através da cobertura vegetal proporcionada, tem sido pouco investigada. Poucos trabalhos tem avaliado esse 
potencial das leguminosas, que se apresenta como um aspecto de muito interesse visto as características já conhecidas dessas espécies.

Este trabalho visa avaliar de maneira mais pormenorizada o potencial das leguminosas utilizadas como adubo verde e plantas de cobertura no controle da erosão. Uma vez constatados, de um lado o papel fundamental da cobertura do solo no controle da erosão, e de outro, as grandes vantagens da utilização das leguminosas no manejo do solo, os resultados a serem aqui obtidos podem se constituir em subsidio para novas alternativas de manejo, como a ut ilização em áreas degradadas, a consorciação com culturas anuais de verão ou culturas perenes no inicio de desenvolvimento entre outros, conseguindo assim um efeito muito interessante no incremento $\theta$ manutenção de altas produções e conservação dos recursos naturais.

Além desse objetivo, o presente trabalho visa avaliar alguns parametros no desenvolvimento do ciclo vegetativo de espécie anual de leguminosa, de modo a conhecer alguns estádios desse ciclo e os limites entre eles. 
2. REVISAOO BIBLIOGAAFICA

2.1. Erosão: Fatores

- processo erosivo é considerado um fenómeno natural do ponto de vista geológico e geomorfológico. A ação de fatores como a chuva e o vento, arrastando partículas do solo e depositando-os em áreas a juzante é considerado um dos principais fatores na formação da paisagem, e cujas perdas ocasionadas são tão diminutas que podem ser compensadas pelo próprio processo de formação do solo.

BENNETT (1947) distinguiu esse processo como sendo denominado erosão geológica ou erosão natural do solo, sendo controlado pera proteção do solo exercida pela vegetação natural presente na região. A substituição dessa vegetação natural pela atividade agropecuária, segundo o autor, traz no entanto como conseqüência a perda da proteção natural do solo, facilitando o processo erosivo com o preparo e manejo intensivos. Em vista disso, as perdas por erosão se tornam muito maiores, ocorrendo de modo centenas de vezes mais rápido graças a ação do homem. Fica assim caracterizada a ação do homem promovendo uma intensificação do processo de erosão hidrica com conseqüencias como a degradação das 
condiçoses do meio, a diminutcăo da diversidade e da vida da flora e fauna a perda das caracteristicas favoráveis para a produção agricola.

2.2. Estimativa das perdas por erosão

A partir do conhecimento dos fatores envolvidos no processo erosivo, os estudos sobre as perdas de solo a agua passaram a procurar detectar o efeito o influencia relativa de cada um. Dessa forma, vártos modelos e equaçós foram desenvolvidas, cada um deles priorizando determinados fatores na erosão.

A partir da junça desses fatores, e após anos de experimentação a nfvel de campo para adaptaço às mais variadas condiçoes ambientais, WISCHMEIER e SMITH (1960) desenvolveram a Equaçăo Universal de Perdas do Solo, que leva em consideraça todos os fatores que influem na erosão. Assim, o modelo ficou sendo definido como:

$$
A=R K \text { LSCP; onde: }
$$

A : perdas de solo por unidade de área ( $t /$ ha)

$R$ : fator erosividade da chuva (MJ $\mathrm{mm} / \mathrm{ha} h$ )

K : fator erodibilidade do solo (t $\mathrm{h} / \mathrm{MJ} \mathrm{mm}$ )

LS: fatores relacionados as condições do terreno, isto é, comprimento da rampa o declividade do terreno (adimensional).

C: fator relacionado ao uso e manejo do solo (adimensional).

$P$ : fator relacionado à adoção de práticas conservacionistas (adimensional). 
os dois últimos fatores tem seus valores como conseqüência direta da ação do homem. Assim, $C$ e $P$ assumem valor unitário em condiçôes de total auŝência de uso racional e adoção de práticas conservacionistas, assumindo valores menores (implicando em menores perdas por erosão) para situações em que medidas de proteção ao solo sejam tomadas. Em relação às equaçōes e modelos utilizados na previsão e quantificação das perdas por erosão, é importante notar que a EUPS tem sido utilizada graças a sua adaptação e eficiencia na previsăo de perdas do solo sob as mais diversas condições. Apesar disso, novos modelos tendem a surgir procurando determinar de forma mais precisa e detalhada não só a quantificação das perdas, mas todas as etapas da ocorrência do processo.

\subsection{O fator $C$ : importancia e subfatores determinantes}

E reconhecido como um fator de extrema importancia, visto ser, ao lado do fator $P$ (práticas conservacionistas) passivel de mudança pela ação do homem.

BERTONI e LOMBARDI NETTO (1990) destacam esse fator como sendo a relação entre as perdas de um solo cultivado em dadas condiços a as ocorridas nesse solo mantido preparado e descoberto. Os autores destacam que, nessa relação, irão influenciar aspectos como a cobertura vegetal, práticas de manejo, sucessão de culturas e o estádio de crescimento e desenvolvimento da cultura no período de maior ocorrência de 
chuvas. Sendo assim, é observada uma estreita relação entre a distribuição anual de chuvas e o periodo da cultura na determinação dos valores do fator $c$.

WISCHMEIER \& SMITH (1960) definiram o fator C da EUPS como sendo a relacão entre as perdas do solo para determinadas condiçóes de uso e manejo e as perdas ocorridas em solo sob condições padrão. Assim, dependendo das condiços de uso e manejo, o fator $C$ assume valores que at enuam a perda de solo ocorrida em função dos fatores $R, K$, $L$ e $S$, e desse modo pode-se compreender a abrangência dos valores numéricos assumidos por este fator na EUPS.

Recentemente, estudos tem sido desenvolvidos com o objetivo de determinar de modo mais fácil o valor do fator $\mathrm{C}$. Estes estudos apontam para a decomposição em subfatores.

MUTCHLER et a1. (1982) estimaram o fator C da EUPS para o algodão, a partir de uma série de sub-fatores como efeito residual do uso e manejo do solo, restos culturais incorporados, intensidade do preparo do solo, microrrelevo - cobertura do solo. Entre esses aspectos, a cobertura do solo apresenta uma ação muito marcante, especialmente para períodos do ano de chuva mais intensa.

LAFLEN et a1. (1985) estimaram o fator c como um produto de subfatores. São assim considerados o uso anterior do solo, a cobertura da copa das plantas (cobertura vegetal), a cobertura morta e a rugosidade da superficie do solo, caracterizando assim subfatores diretamente dependentes das condições de uso e manejo. Em relação a cobertura vegetal, 
esse subfator é avaliado a partir de aspectos como a fração da superficie do solo coberta e a altura média das copas.

WISCHMEIER e SMITH (1978) consideraram ainda a importância da distribuição da erosividade anual da chuva para a região aonde a cultura está instalada. Assim, a partir da combinação desses fatores (RPS e percentual da erosividade anual para cada perfodo da lavoura) será estabelecido o fator $C$ da EUPS. Desse modo pode-se concluir pela importância da RPS, essencial na determinação do fator $C$.

Para efeito de cálculo do fator $C$, os autores destacam a importância da obtenção do valor da Razão de Perdas do solo (RPS) para as condições de uso manejo do so10. A RPS se constitui também em uma relação entre perdas do solo sob determinadas condições de uso e manejo e as perdas sob condições padrão, obtida para perfodos menores (subdivisões do ano agrícola) denominados períodos de lavoura. Assim, durante esses perfodos da lavoura, o solo se encontrará sob condições uniformes no que diz respeito a condições de proteção contra erosão, seja pela manutenção do solo preparado sob determinado sistema ou um determinado estádio de desenvolvimento da cultura.

A divisão do ciclo das culturas é feita considerando-se como 1 imites entre períodos algumas operações como preparo do solo, semeadura e colheita, assim como estádios de desenvolvimento da cultura. 
A definicão dos limites entre os perfodos da lavoura pode se dar ainda sob vários critérios, como operaçóes de cultivo (KRAMER \& ALBERTS, 1986), a obtenção de determinados percentuais de cobertura do solo (MUTCHLER et a)., 1982), ou perfodos de tempo previamente determinados (DECHEN et a 1., 1981). No presente trabalho, os limites serão estabelecidos a partir da cultura (Crotalaria juncea L.) na primeira etapa do trabalho em relaçă aspectos considerados.

\subsection{Efeitos da cobertura do solo}

A partir da análise mais aprofundada dos subfatores componentes do fator " $c$ " da EUPS, foi sendo cada vez mais destacada a importância da cobertura do solo, seja pela cultura ou pelos restos de culturas, no controle da erosão. Em estudos relativos a aspectos físicos do solo, BAVER (1948) declara que a ação da cobertura do solo no controle da erosão se dá sob várias formas, como a quebra do impacto da gota de chuva, a açăo como obstaculo freando a velocidade da enxurrada e sua capacidade de arraste das particulas; o efeito de sistema radicular e restos vegetais no solo aumentando a sua agregaça e porosidade; a maior atividade microbiana e a secagem mais rápida pelas maiores taxas de evapotranspiração. Essas informações são confirmadas por BERTONI (1959) que atesta a maior infiltração de água no solo em perfodos do ano em que a presença de maior 
vegetação implica em uma distribuiçăo de raizes formando pequenos canais, aumentando o fluxo de água. Como se pode observar, os aspectos favoráveis citados por esses autores dizem respeito tanto a condicões de cobertura vegetal (culturas instaladas) como cobertura morta (restos de cultura).

Essas consideraçōes são reforçadas por um grande número de trabalhos, que procuram também quantificar a açăo da cobertura do solo no controle da erosão. Assim, ELWELL STOCKING (1976) estimam que a partir de um percentual de cobertura vegetal em torno de $60 x$, as perdas de solo tornamse bastante reduzidas, não havendo diminuiçăo significativa com o aumento dos niveis de cobertura. MANNERINa a MEYER (1963), estudando o efeito da cobertura do solo com restos de culturas do trigo atestam que, a partir de uma quantidade de $1 \mathrm{t} /$ acre nota-se uma reduçăo da erosão a niveis minimos. Os autores ressaltam como principais causas dessa redução maior infiltração de água no solo, resultando em menor volume de enxurrada, e também na menor velocidade desta última com menor arraste das partículas do solo.

Outras culturas foram igualmente testadas quanto a capacidade protetora exercida por seus residuos contra a erosão. GILLEY et al. (1986) estudaram o efeito dos residuos do milho no controle da erosão em diversas quantidades de palha, sob condiçóes de chuva simulada. Várias correlações foram conseguidas, com perdas de solo, água e percentuais de cobertura morta. Os resultados 
mostraram que, a partir de percentuais em torno de $40 x$ de cobertura morta, valores obtidos para o fator "Mulch" (relação entre perdas de solo com o tratamento e sem qualquer tipo de cobertura) chegaram próximos a zero.

Também em relaçao aos restos do milho, LOMBARDI NETO et a 1. (1988) encontram uma relaçăo exponencial entre a quantidade de restos de culturas e a diminuição das perdas por erosão. E interessante notar que, nesse trabalho, os autores mostram que o efeito da cobertura morta torna-se mais efetivo com o aumento do potencial erosivo da chuva, conforme e mostrado pelos valores do fator cobertura vegetal (FCV).

Em relação a cultura da aveia, SINGER et al. (1981) conseguiram uma relação linear entre quantidades crescentes de cobertura do solo e diminuiçăo de perdas, para valores entre 0 e 2,2 t/ha de restos de cultura. Esses dados foram obtidos para perdas provocadas pelo impacto da gota de chuva - pela enxurrada, separadamente.

o efeito diferenciado de tipos distintos de cobertura morta também -identificado em trabalho de SINGER e BLACKARD (1978), através do teste de restos de aveia e folhas de sequoia e carvalho. Foram relacionadas as variáveis quantidade de resíduos das trés espécies, percentual de cobertura morta atingido e efeito nas perdas de solo e água, e entre os materiais testados os restos de culturas da aveia apresentaram, para mesmas quantidades de residuos, a maior cobertura do solo e melhor controle da erosão. Esse comportamento diferenciado se deve às formas e 
tamanhos dos materiais utilizados, resultando em maior ou menor eficiência na proteção do solo contra o impacto da gota de chuva e na formação de obstáculos contra a enxurrada.

LOPES et al. (1987), relacionaram a redução das perdas por erosão com quantidades crescentes de resíduo. Avaliando-se as culturas do milho, trigo e soja, os restos de culturas do trigo apresentaram maior eficácia no controle da erosão, em relação as perdas em terreno descoberto. Isso pode ser explicado pelo fato de os residuos do trigo, de menor comprimento e espessura, possibilitarem uma cobertura do solo mais uniforme, e consequentemente mais efetiva. Os autores relacionam ainda as quantidades de restos culturais com a porcentagem de cobertura do solo proporcionada, e as características dos resíduos de trigo mostrararam-se as mais sat isfatorias.

A cobertura do solo por culturas instaladas, reflorestamento ou vegetação natural também irá exercer apreciável efeito no controle da erosão, devido a aspectos já citados na interferência na relação entre o solo e os agentes erosivos. Em discussão a esse respeito, WISCHMEIER e SMITH (1978) mostram que a ação da cobertura vegetal é muito pouco efetiva como obstáculo ao defluvio superficial, se comparada a cobertura morta. Em relação á quebra do impacto da gota de chuva, essa será tanto maior quanto menor for a altura da planta, visto que na trajetoria de queda entre a parte aérea - solo uma boa parte da energia cinética pode ser recuperada, especialmente para culturas de maior porte. 
Ainda segundo os autores, o efeito ótimo seria conseguido com a combinação adequada da cobertura morta e culturas instaladas nas áreas de uso agrícola.

STOCKING (1988) citou uma série de vantagens da cobertura do solo, destacando aspectos relativos a cobertura vegetal por vegetaça natural ou cultura instalada, como a proteção contra o impacto da chuva pela parte aérea da planta e a ação do sistema radicular na maior infiltração de água e secagem do solo. Em contrapartida såo colocados alguns aspectos negativos, como o fato de plantas de alto porte permitirem que gotas de chuva se juntem na sua parte aérea e caiam ao solo com maior massa e conseqüentemente considerável energia cinética. Ao mesmo tempo, vegetação de maior porte exerce severa competicão por água e luz com plantas mais rasteiras, que normalmente apresentam maior proteção ao solo, e desse modo facilitam o processo erosivo. Essas observações são confirmadas por MORGAN (1985) em trabalho de modelagem da ação desagregadora das gotas de chuva sobre o solo em função da presença de cobertura vegetal. Os dados coletados demonstraram uma diminuição do percentual de energia cinética total da chuva que chega a superfície do solo, a medida que aumentam os percentuais de cobertura.

Alguns efeitos negativos já citados também foram notados, e o comportamento geral de cada espécie de planta variou conforme a cobertura proporcionada, a altura (porte) da planta e a distribuição e forma das folhas. o tipo de cobertura vegetal fica assim caracterizado como um aspecto 
fundamental na abrangência da ação da cobertura na proteção contra a erosão. CHISCI e ZANCHI (1981), comparando o uso de pastagens cont inuas com culturas instaladas deixaram evidente esse aspecto, obtendo valores significativamente menores para perdas de solo para o primeiro uso. Esses resultados, assim como os obtidos em outros trabalhos, evidenciam a importância e a praticidade do fator uso e manejo do solo no controle da erosão.

2.5. Leguminosas na conservaçăo do solo

Dentre as plantas de importancia agrícola já conhecida, as espécies pertencentes a familia das leguminosas apresentam destaque pelo grande número e amplas possibilidades de utilização. Assim, além da presença de várias espécies de valor económico decorrente da sua utilização na alimentação e do processamento industrial, cabe destacar a larga aplicação com fins de melhoria das condições do solo no que diz respeito as suas características físicas e químicas.

Essas propriedades das leguminosas fazem com que sejam as espécies preferidas para a prática da adubação verde. Segundo MIYASAKA (1984), as vantagens do uso das leguminosas nessas condições são devidas a fatores como uma relação $C: N$ bastante favorável para a mineralização, o alto teor de Nitrogênio (inclusive através da fixação simbiótica com Rhizobium) constituindo-se em fonte de suprimento para o so10; a liberação mais eficiente de nutrientes outros para o 
solo; a grande produção de massa verde, etc. Dessa forma, o autor conclui, a partir das caracteristicas encontradas nessas espécies, pela conveniência do uso de leguminosas em rotação de culturas, refletindo em aumentos de produtividade nas culturas sucessoras. PEETEN (1984) deixou claro a importância e a eficiência de leguminosas na conservação do solo, a partir dos bons nfveis alcançados na cobertura do solo. Entre as conseqüencias benéficas citadas, mereceu especial atenção a proteção contra erosão conseguida graças a cobertura proporcionada pela cultura instalada ou restos de culturas.

A utilização do potencial das leguminosas pode ser feita de diferentes formas, de acordo com a finalidade. BULISANI e BRAGA (1985) destacaram a utilização em rotação de culturas, como opção de outono-inverno. o sistema de produção associado a intensa utilização de insumos e tecnologia irá implicar na necessidade da escolha de espécies de algum retorno económico, dada a quantidade de investimentos. Os autores citaram também as opções do uso de leguminosas em consorciação com outras culturas anuais, como no caso da mucuna (stizolobium aterrinum)-milho, e também como cobertura de solo e adubo verde no plantio em entrelinhas em áreas destinadas a fruticultura de clima tropical ou de clima temperado. Estas colocações possibilitam considerar as leguminosas não só como opções de inverno, mas tambem como espécies úteis para o plantio de verão, visto ser esse perfodo o mais propicio para eventos 
como a erosão e a infestação por plantas invasoras.

EL SWAIFY et a1. (1988) estudando o efeito da consorciação de culturas de milho e mandioca com algumas leguminosas, encontraram efeitos positivos na redução da erosão comparativamente aos resultados obtidos para culturas "solteiras" ou solo descoberto. Assim, a cultura do milho consorciada a trevo-rosa (Trifolium hortum L.) e cornichão ( Lotus corniculatus L.) apresentou efetiva reduça nas perdas do solo, assim como na consorciação mandioca/amendoim, essa porém com menor efeito.

BERTONI et al. (1972) destacaram ainda a respeito das leguminosas a capacidade de rápida germinação, crescimento e estabelecimento da planta, caracterizando-as como de grande ut ilidade para a proteção de áreas descobertas em taludes ou encostas.

Em relação às espécies mais utilizadas como adubo verde e para proteção e melhoramento das condições do solo em geral, MIYASAKA (1984) relacionou uma série de espécies que merecem destaque para as condições do Estado de São Paulo. Como exemplo pode-se citar as espécies Crotalaria juncea L., Crotalaria paulina L.; o feijão guandu (Cajanus cajan L.), a mucuna-preta e a mucuna anã (stizolobium sp.), o Dolichos lablab L. e o feijão de porco (Canavalia ensiformes D. C.). - autor relatou ainda algumas características importantes dessas espécies, que tem influência direta na eficiência como ádubo verde e a proteção do solo. Como exemplo, pode-se notar que tratam-se de espécies altamente 
sensiveis ao fotoperíodo, tendo geralmente indução ao florescimento em dias curtos, e desse modo a semeadura no periodo outubro-Janeiro irá implicar em maior produção de biomassa enquanto no inverno tem-se um florescimento precoce e menor desenvolvimento.

Para o caso de semeadura no verão o florescimento e inicio da formação de vagens ocorre entre 120 e 150 dias, segundo SALGADO et al. (1990), sendo esse período o ideal para o corte, quando o objetivo é a utilização para adubação verde.

Em relação ao porte das plantas, as leguminosas podem apresentar porte baixo, geralmente associados a alta produção de biomassa (aproximadamente $25 \mathrm{t} / \mathrm{ha}$ ) como no caso da mucuna e feijão-de-porco. Espécies como crotalária e feijão-güandu, por sua vez apresentam maior altura de plantas, porém, normalmente com porte mais ereto e menor produção de massa verde.

AMADO (1990), estudando a velocidade de desenvolvimento e a cobertura vegetal proporcionada por uma série de adubos verdes, destacou a mucuna-preta como de maior velocidade de crescimento, atingindo cobertura vegetal de 50\%, cerca de 38 dias após o plantio. Além disso, algumas espécies de mucuna (entre as quais a mucuna-preta) e o labelabe estiveram entre os adubos verdes que atingiram percentuais de cobertura vegetal proximos a $100 \%$.

E também importante a ação do sistema radicular de algumas leguminosas, que com grande vigor e comprimento 
algumas vezes superior a $1,0 \mathrm{~m}$, possibilita a transferência de nutrientes de camadas mais profundas do solo para as mais superficiais, por ocasião do seu corte e manutenção na superficie do solo. Além disso, o problema da presença de camadas compactadas pode ser ao menos atenuado com o desenvolvimento das raizes dessas espécies.

Alguns trabalhos atestam a eficiencia dessas especies como adubos verdes. VEIGA et al. (1977) em experimento que associou a ação da calagem e da adubação verde com Crotalaria juncea L. na produção do feijoeiro, destacam que a partir da quarta safra os efeitos da leguminosa como adubaça verde passam a ser significativos. Isso caracteriza principalmente os efeitos a longo prazo, porém bastante estáveis e duradoùros, da leguminosa nas características físicas do solo. MASCARENHAS et al. (1987) demonstram também a ação de curto prazo da adubação verde através da ervilhaca na produção de feijão. É interessante notar que os autores encontram menor eficiencia da adubaçao mineral nitrogenada com a presença da adubação verde, deixando claro o suprimento daquele elemento pela leguminosa, diminuindo assim a influência da adubação mineral.

As investigações sobre a proteção do solo exercida por leguminosas durante seu ciclo podem auxiliar na determinação de outro fator positivo na utilização dessas espécies, além dos já conhecidos. 
3. MATERIAL E METODOS

3.1 . MATERIAL

o material utilizado constou de:

3.1.1. Caracterização do local

o presente trabalho foi realizado com dados obtidos pela Seção de Conservação do Solo, no Centro Experimental de Campinas do Instituto Agronómico do Estado de são Paulo, Brasil (Figura 1).

- Centro Experimental de Campinas está localizado de acordo com as coordenadas geográficas $22^{\circ} 54^{\prime} \mathrm{S} 47^{\circ} 05^{\prime} \mathrm{W}$. A altitude varia de 600 a $720 \mathrm{~m}$ e sua área total é de $767 \mathrm{ha}$. A precipitação média anual é de $1.380 \mathrm{~mm}$, a temperatura média anual é de $20,7^{\circ} \mathrm{C}$. O tipo climático é Cwa, de acordo com o critério de Koeppen, definido como mesotérmico úmido com verão quente. A Figura 2 apresenta o balanço hídrico decendial para o ano agricola 1990/91.

o solo onde as parcelas experimentais ficaram instaladas é um Latossolo Roxo Distrófico, A moderado, textura argilosa, unidade Barão Geraldo (Typic Haplorthox).

Na Tabela 1 encontram-se atributos do horizonte superficial do solo estudado, conforme DENARDIM (1990). 


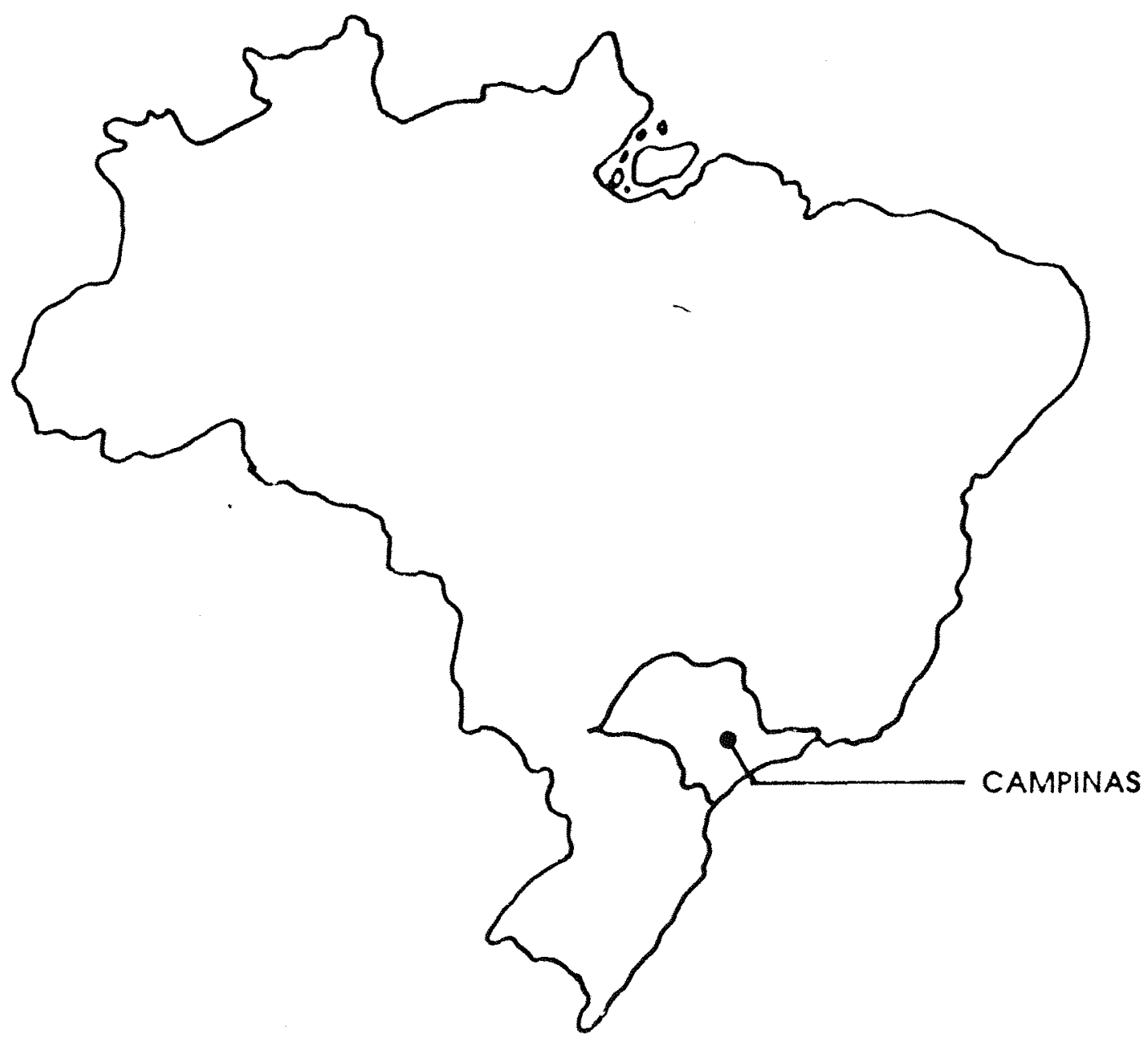

Figura 1. Mapa mostrando a localização do município de Campinas. 


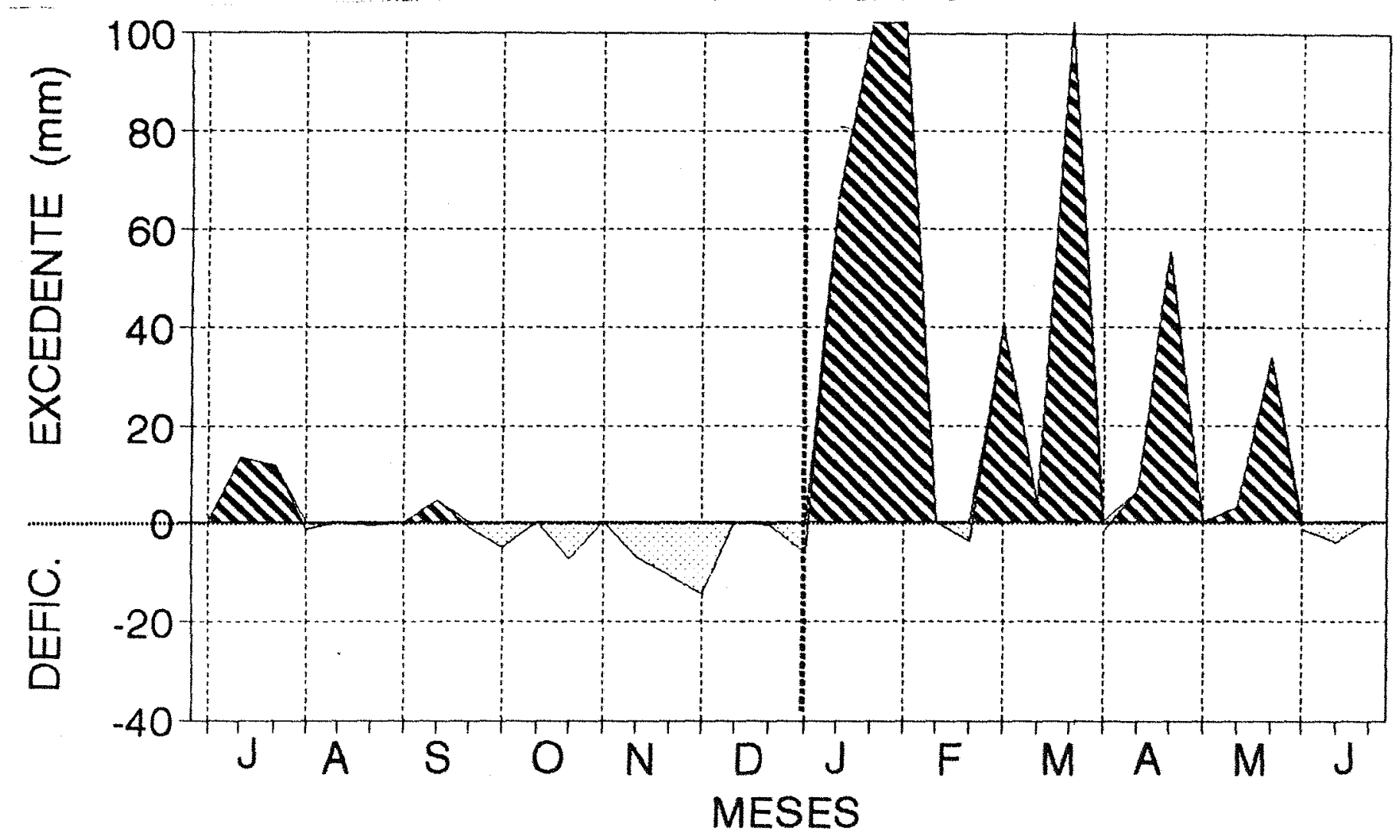

Figura 2. Balanço hídrico decendlal para Camplnas, SP no ano agrícola 1990/91

Fonte: Seção de Climatologia Agrícola, IAC. 
Tabela 1. Caracteristicas do horizonte superficial $(0-20 \mathrm{~cm})$ do latossolo roxo distrofico, unidade Barão Geraldo

\begin{tabular}{lc}
\hline Atributos & \\
\hline Classe textural & Argilosa \\
Argila $(\%)$ & 48,6 \\
Silte $(\%)$ & 18,5 \\
Areia $(\%)$ & 32,9 \\
Matéria Orgânica $(\%)$ & 2,30 \\
\hline
\end{tabular}

Fonte: DENARDIM (1990)

As caracteristicas das parcelas de campo e dos sistemas coletores de solo e enxurrada seguem as especificações de BERTONI (1949). As referidas parcelas tem uma área de $100 \mathrm{~m}^{2}$, com $25 \mathrm{~m}$ de comprimento no sentido do declive por $4 \mathrm{~m}$ de largura e declive uniforme de 12,9 e $9,9 \%$ para os dois grupos, com 8 e 14 talhões, respectivamente.

O sistema coletor de solo e enxurrada, adaptado a jusante da soleira das parcelas, foi construido de alvenaria, inclusive a soleira e a parede divisoria. Possui dots tanques ligados por um divisor de janelas do tipo Geib para fração de $1 / 7$. O primeiro, acoplado à soleira, destina-se à decantação do solo arrastado pela enxurrada, enquanto que o segundo, acoplado ao primeiro, capta $1 / 7$ da enxurrada.

Em local próximo, está instalado um pluviómetro que, a cada ocorrência de precipitação, possibilita a avaliação do seu total, e também de um pluviógrafo que permite o conhecimento preciso da duração e hora de ocorrência, assim como as variações de sua intensidade. 
3.2. METODO

3.2.1. Avaliação do desenvolvimento da Crotalaria juncea L.

Durante o ano agrícola de 1990/91, em quatro talhões experimentais de avaliação de perdas do solo com declividade de $12,9 \%$, foi semeada a Crotalaria juncea L.. A área foi submetida a preparo do solo feito manualmente em $20 / 12 / 90$ e semeadura realizada em $27 / 12 / 90$, em contorno, com espaçamento de $0,50 \mathrm{~m}$ entre linhas e 30 sementes por metro.

Foram realizadas determinaçōes de cobertura vegetal - altura de plantas, bem como das perdas de solo devidas as chuvas ocorridas no período. Estas avaliações foram realizadas no período de 0 a 90 dias apos a semeadura.

3.2.2. Avaliação da Razão de Perdas de solo para três Teguminosas

No período de $1973 / 74$ a $1978 / 79$ foram instaladas em três talhões experimentais de avaliação de perdas de solo os seguintes tratamentos:

1) Crotalária (Crotalaria juncea L.): plantio em nivel, com espaçamento de $0,50 \mathrm{~m}$ entre linhas e 30 sementes/m.

2) Mucuna-preta (stizolobium aterrinum Piper et Tracy): plantio em nível, com espaçamento de $0,50 \mathrm{~m}$ entre 1 inhas e 7 sementes viáveis/m linear. 
3) Labelabe (Dolichos lablab L.): plantio em nivel, com espaçamento de $0,5 \mathrm{~m}$ entre 1 inhas e 10 sementes $/ \mathrm{m}$.

Essas espécies foram semeadas como cultura de verão durante seis anos consecutivos.

As datas de operaçóes das instalações de culturas, encontram-se na Tabela 2 .

Tabela 2. Seqüência de operações de instalação de culturas, no período $1973 / 79$

\begin{tabular}{cccc}
\hline Ano agricola & Preparo & Plantio & Corte \\
\hline & $25 / 09$ & $18 / 10$ & $06 / 03^{*}$ \\
$73 / 74$ & $03 / 10$ & $25 / 10$ & $26 / 02^{2}$ \\
$74 / 75$ & $08 / 10$ & $05 / 11$ & $26 / 02^{(1)}$ \\
$75 / 76$ & & & $10 / 03^{(2)}$ \\
& $13 / 09$ & $18 / 10$ & $03 / 03^{(1)}$ \\
$76 / 77$ & $05 / 09$ & $04 / 10$ & $12 / 04^{(2)}$ \\
$77 / 78$ & $16 / 09$ & & $29 / 03^{(1)}$ \\
$78 / 79$ & & $16 / 10$ & $15 / 05^{(2)}$ \\
& & & $22 / 03^{(2)}$ \\
\hline
\end{tabular}

* menos para labelabe que não sofreu corte no 10 ano.

(1) para a Crotalaria juncea

(2) para o labelabe e mucuna-preta

Após a corte, os restos de cultura foram mantidos na superfície do solo, até o preparo para nova semeadura, quando, eram incorporados ao solo. No mesmo período um talhão foi mantido descoberto, com as operações de preparo de 
solo efetuadas na mesma data em relação aos talhões com leguminosas, com o solo mantido descoberto e freqüentemente capinado.

Para a avaliação da razáo de perdas de solo (RPS) para as três leguminosas utilizaram-se os valores médios de perdas de solo obtidos em 6 anos de determinaçăo, para cada estádio em que foi subdividido o ciclo das leguminosas.

\subsubsection{Coleta de dados}

A coleta de dados nos dois perfodos do trabalho foi feita a partir dos seguintes procedimentos:

\subsubsection{Perdas de solo}

A determinação de perdas de solo foi realizada após a ocorrência de cada chuva que causasse perda de água e/ou solo, e tabuladas segundo procedimento da seção de Conservação do solo da IAC (BERTONI \& LOMBARDI, 1990).

Para as perdas de solo no perfodo de $1973 / 74$ a 78/79 foi procedida uma correção em relação ao declive de $12,9 \%$ dos talhões das leguminosas para o talhão descoberto que se encontrava em declive de 9,9\%. Para essa correção foi utilizada a equação de LOMBARDI NETO (1977) resultando um fator igual a 0,7358 . 


\subsubsection{Cobertura do solo}

Para a avaliação da cobertura vegetal foi utilizado - ano agricola $90 / 91$, nos quatro talhões com leguminosas. 0 método utilizado foi a Armação de Visadas Localizadas (ELWELL E WENDELAAR, 1977 ).

A localização das áreas para a determinação foi feita através da escolha de 3 subparcelas, para cada talhão, nas porções superior, média e inferior do talhão, com área de $1 \mathrm{~m}^{2}$ cada.

o equipamento utilizado consta de 10 visores espaçados de $10 \mathrm{~cm}$, acoplados em uma barra de $1 \mathrm{~m}$. Após efetuar-se a leitura para todos os visores da barra, o aparelho era movimentado $10 \mathrm{~cm}$ para a frente, em uma nova linha de observação. Cada subparcela apresentava 10 linhas de observação, totalizando 100 visadas. A Figura 3 apresenta um esquema da movimentação do aparelho em cada subparcela.

Os valores de cobertura de solo para cada visada, foram atribuídos através da estimativa de frações da visada interceptada pelo dossel da planta, sendo essas frações encaixadas em cinco valores $(0 ; 1 / 4 ; 1 / 2 ; 3 / 4 ; 1)$. A partir da soma total dos valores obtidos para cada subparcela, foram calculados os percentuais de cobertura do solo, e a média das três observações, constituiu-se no valor de cobertura do solo para o talhão. 
Decllve

- Tonques Coletores

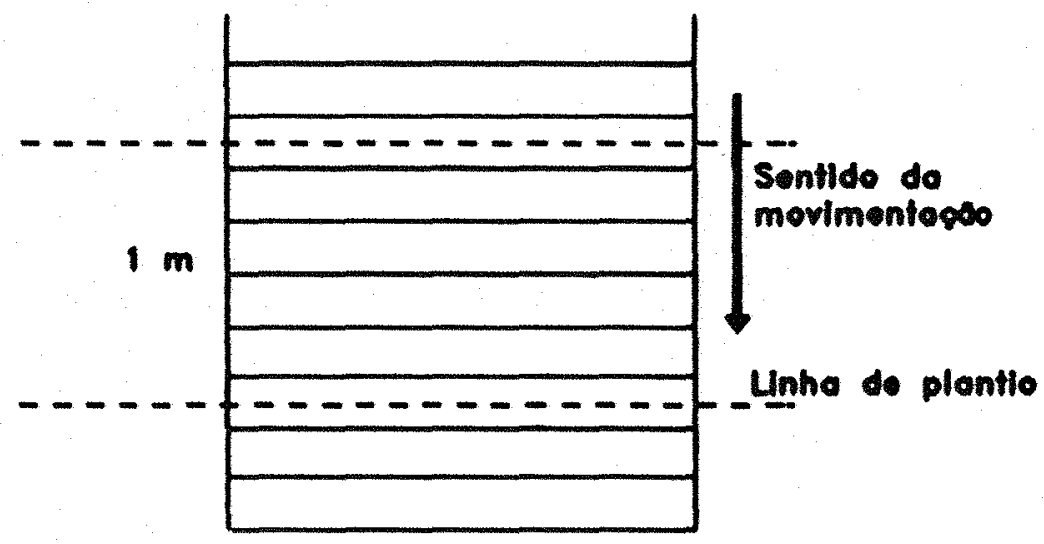

$1 \mathrm{~m}$

$-\cdots-\cdots-\cdots-\cdots-\cdots-\cdots-\cdots$

ESCALA 1:20

- - - Unho de plontlo

Posiges de barra de

visados do oporolho

Figura 3. Esquema de movimentação da Armação de Visadas Localizadas para a avaliação da cobertura vegetal da Crotalaria juncea L.

o percentual de cobertura vegetal, assim, pode ser determinado pela seguinte expressão:

$8 C . V .=\frac{\sum \text { das visadas interceptadas }}{100} * 100$

A movimentação do aparelho para as determinações foi feita perpendicularmente às linhas de plantio, ao contrário do recomendado pelos autores. Também a presença muito adensada das plantas em cada linha de plantio 
dificultou a movimentação do aparelho, prejudicando a operacionalidade e precisão dos resultados.

A avaliação da cobertura do solo fol programada para realização periódica, em intervalos de 3 a 4 dias entre uma outra. A germinação o desenvolvimento inicial das plantas ocorreram em tempo maior do que o esperado, e de maneira irregular, fazendo com que a primeira avaliacão ocorresse 13 dias após a semeadura. Também a partir de cerca de 30 dias após a semeadura, o crescimento das plantas trouxe alguns problemas para a execuça da avaliação. Algumas alternativas foram testadas para que se pudesse continuar as avaliaçoes de cobertura vegetal, optando-se pela colocação de uma barra de espelho abaixo das visadas, permitindo a estimativa de cobertura das partes da planta situadas acima do aparelho.

outros fatores, como a ocorrência de chuvas, também prejudicaram a regularidade na freqüencia das observaçós.

\subsubsection{Altura das plantas}

A avaliação da altura das plantas foi feita toda vez que se efetuava a avaliaçăo da cobertura do solo. Em cada subparcela do talhão, 10 plantas eram tomadas ao acaso, sendo medida a altura compreendida entre o colo o ópice das plantas. A partir da obtençao dos valores, as médias foram calculadas para cada subparcela, tendo-se assim três valores médios para cada talhão, referentes as subparcelas das 
porções superior, média e inferior.

Um novo valor médio foi obtido a partir dos três resultados, constituindo-se na média geral do talhão para aquela avaliação.

3.2.3.4. Produção

As produções das leguminosas foram avaliadas em termos de massa verde e peso seco, no ano agrícola 1990/91.

3.2.4. Análise dos dados

Para a ańlise dos dados referentes ao ano agrícola 90/91, utilizou-se de um programa de ajuste de dados desenvolvido por zULLO \& ARRUDA (1986) onde vários modelos foram testados. 
4. REsUltados e discussão

4.1. Avaliação do desenvolvimento da Crotalaria juncea

A Crotalaria juncea L. foi avaliada durante 0 ano agrícola 90/91 em relação a aspectos de altura de plantas, cobertura vegetal do solo e da produção de massa em peso seco após o corte.

A Tabela 3 apresenta a altura das plantas, cobertura dó solo, perdas de solo e precipitaçăo pluviométrica.

Tabela 3. Avaliação da altura de plantas, cobertura vegetal, perdas de solo e precipitação pluviométrica acumulada para o período de estudo da Crotalaria juncea

\begin{tabular}{|c|c|c|c|c|}
\hline $\begin{array}{c}\text { Dias } \\
\text { após } \\
\text { semeadura }\end{array}$ & Altura & $\begin{array}{c}\text { Cobertura } \\
\text { do } \\
\text { solo }\end{array}$ & $\begin{array}{l}\text { Perdas } \\
\text { acumuladas } \\
\text { de solo }\end{array}$ & $\begin{array}{c}\text { Precipitação } \\
\text { pluviometrica } \\
\text { acumulada }\end{array}$ \\
\hline & $\mathrm{cm}$ & $x$ & t/ha & $\mathrm{mm}$ \\
\hline $\begin{array}{c}0 \\
13 \\
16 \\
21 \\
24 \\
29 \\
52 \\
71 \\
78\end{array}$ & $\begin{array}{r}0,0 \\
9,8 \\
12,5 \\
16,6 \\
19,3 \\
23,3 \\
50,4 \\
90,4 \\
105,9\end{array}$ & $\begin{array}{r}0,0 \\
17,5 \\
17,2 \\
22,1 \\
25,3 \\
26,5 \\
23,5 \\
42,3 \\
36,3\end{array}$ & $\begin{array}{c}0,0 \\
8,16 \\
8,16 \\
19,83 \\
20,94 \\
29,62 \\
37,13 \\
42,03 \\
44,39\end{array}$ & $\begin{array}{r}0,0 \\
189,0 \\
189,0 \\
396,9 \\
411,3 \\
543,6 \\
649,7 \\
792,1 \\
881,1\end{array}$ \\
\hline
\end{tabular}

plantio: 27/12/90

florescimento: 23/03/91 - produção de biomassa (seco) - $1.148 \mathrm{~kg} / \mathrm{ha}$ médias de 4 repetições 
A Figura 4 apresenta a avaliação da altura da planta em função do tempo, mostrando um alto coeficiente de determinação $(0,9976)$, sendo que em limites situados aproximadamente aos 30 e 60 dias encontra-se uma tendéncia de aumento do ritmo de crescimento das plantas.

As figuras 5 e 6 apresentam as variaços da cobertura do solo da crotalaria juncea em funça do tempo e da altura, respectivamente.

Os dados de cobertura do solo mostram uma grande variação devida a vários problemas ocorrido durante o desenvolvimento da crotalária, como plantio tardio, germinação, irregularidades do estande, o próprio método de avaliação da cobertura além de que o período de 27 de dezembro a 23 de março, apresenta uma precipitação pluviométrica $47 \%$ superior a média para um perfodo de 25 anos. A figura 2 mostra, também, que apesar da alta pluviosidade nesse periodo, houve um veranico (deficit hídrico) no segundo decêndio de fevereiro.

- espacamento da crotalária impediu que a movimentação do equipamento de leitura estivesse no sentido paralelo as linhas de plantio, sendo que a leitura foi feita perpendicularmente, ao contrário do citado por ELWELL e WENDELAAR (1977). 


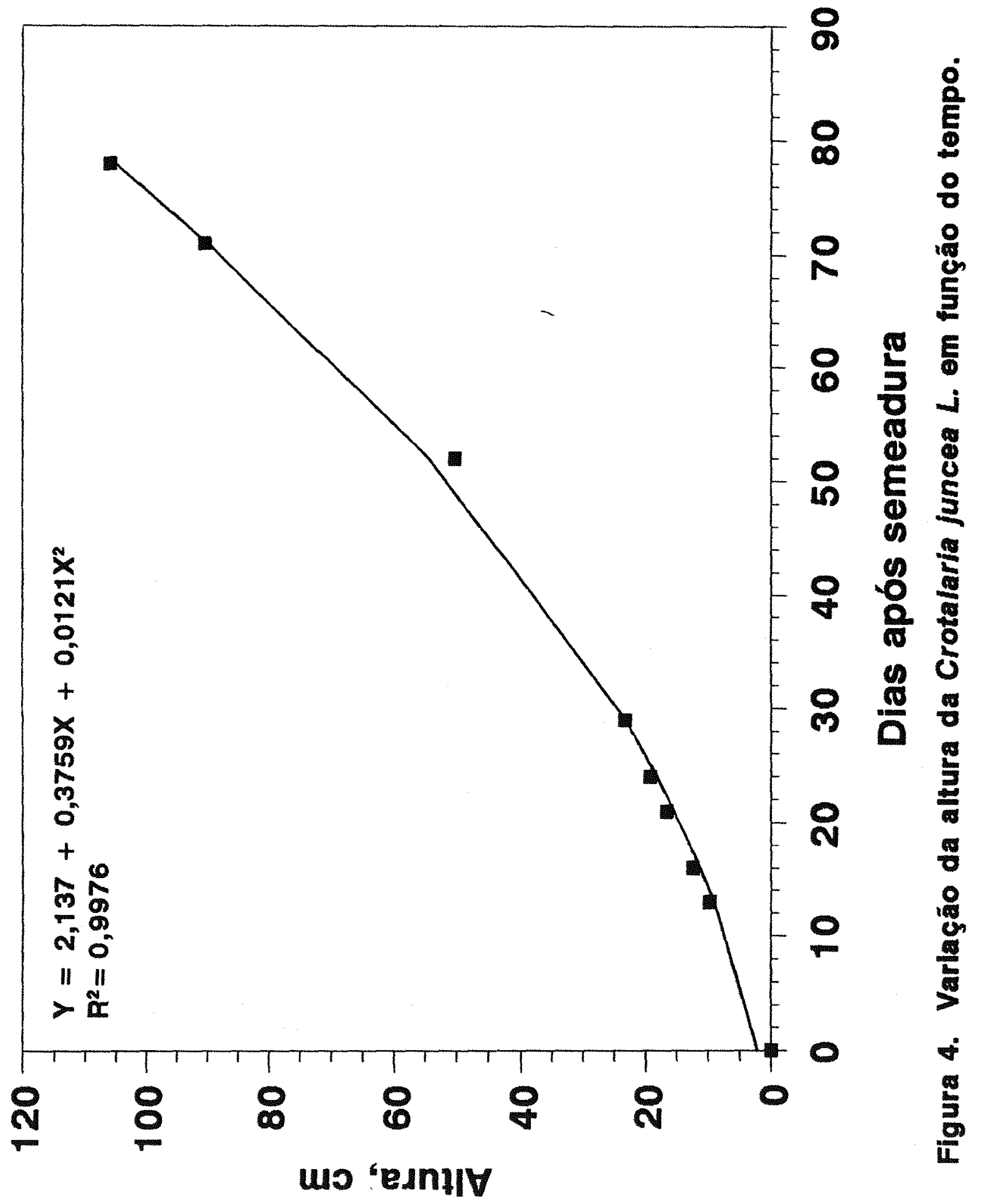




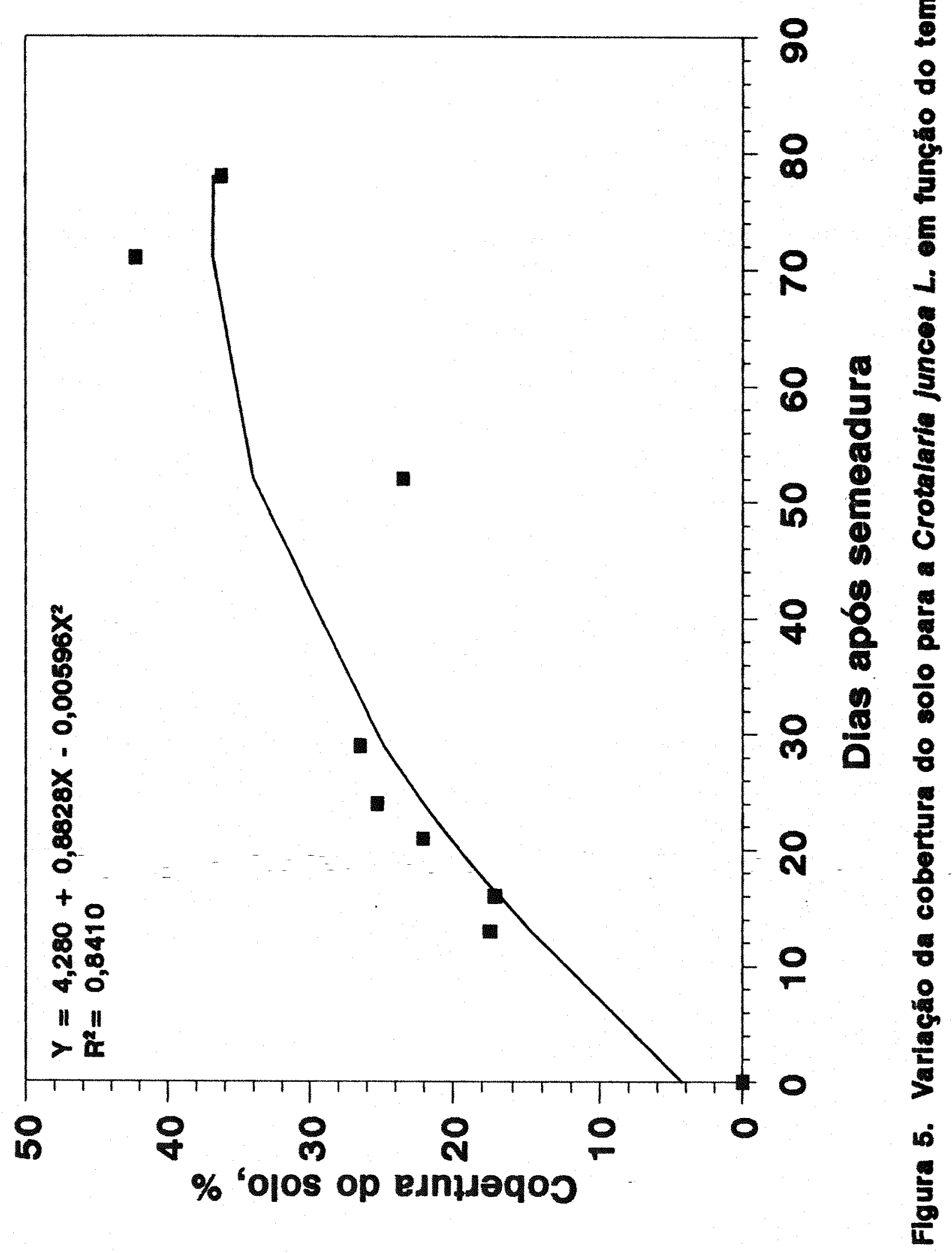




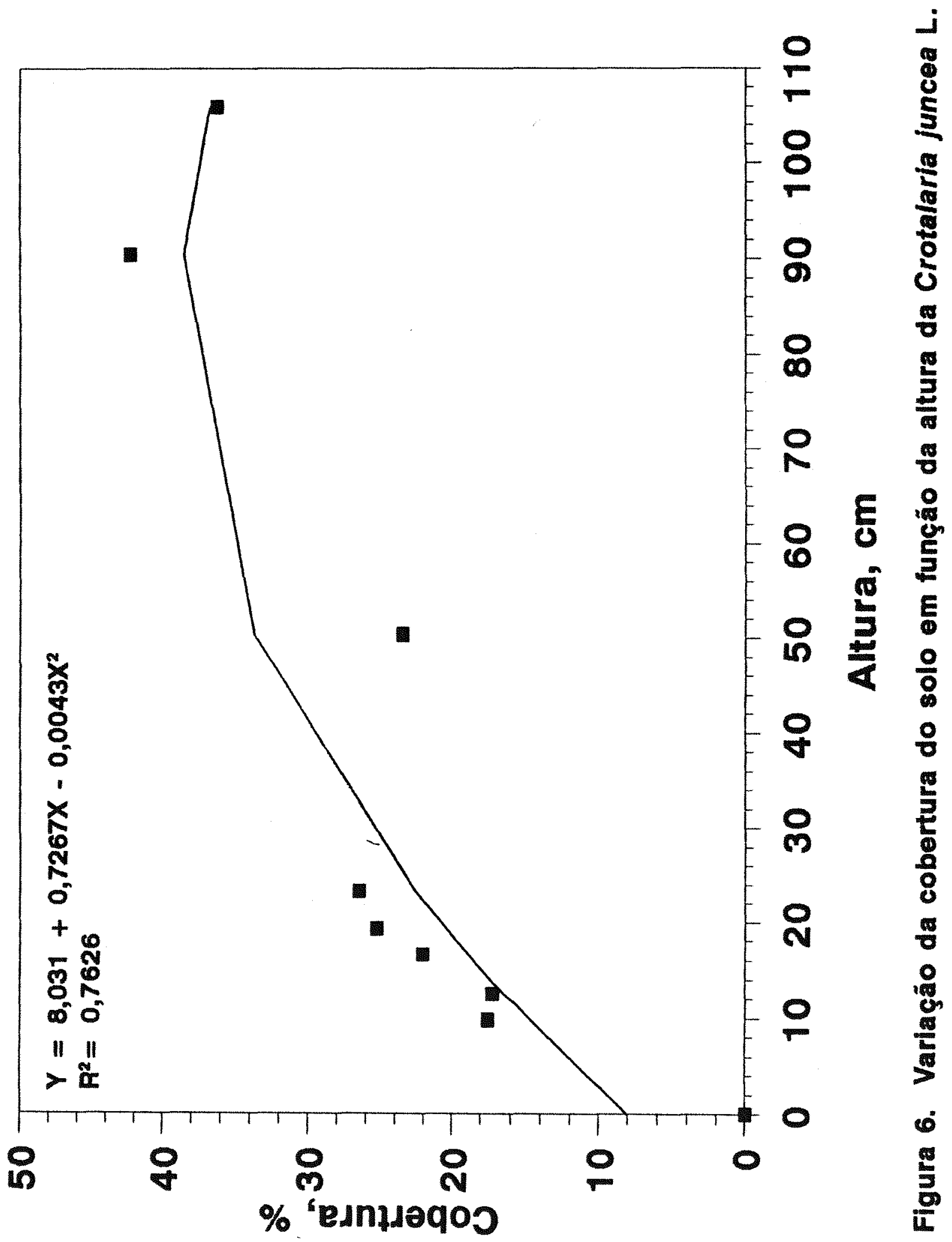


A adaptação feita no aparelho, com utilização de uma barra de espelhos para a estimativa da cobertura, também influenciou nos resultados. A partir daí notou-se uma queda nos valores obtidos para a cobertura do solo (ao redor de 40 dias). ELWELL $\theta$ GARDNER (1976), também const ataram uma menor eficiencia desse método para a avaliação da cobertura em culturas de maior porte.

As Figuras 7 e 8 mostram as variações de perdas de solo acumuladas em função do tempo e da altura da crotalária, observando que ao redor dos 30 e 60 dias após o plantio houve uma tendência de variação das perdas de solo, isto é, as perdas diminuiram com o aumento da altura da crotalária e por conseguinte com o aumento da cobertura do solo.

As análises das figuras 4 a 8 pode caracterizar trés fases para a cultura da crotalária: da semeadura aos 30 dias, dos 30 ao 60 dias $e$ de 60 ao florescimento.

A crotalária tem um crescimento rápido, porém sendo do tipo erecto não implica na formação de um dossel que proporcione maior cobertura (WUTKE, 1993). Essa característica é bastante variável de acordo com a espécie de leguminosa, espaçamento e época de plantio.

Como o florescimento das leguminosas de verão destinadas a adubação verde ocorre entre 90 e 120 dias (MYASAKA, 1984; WUTKE, 1993) foram estabelectdas como alternativas para o terceiro período, o corte aos 90 ou 120 dias. 


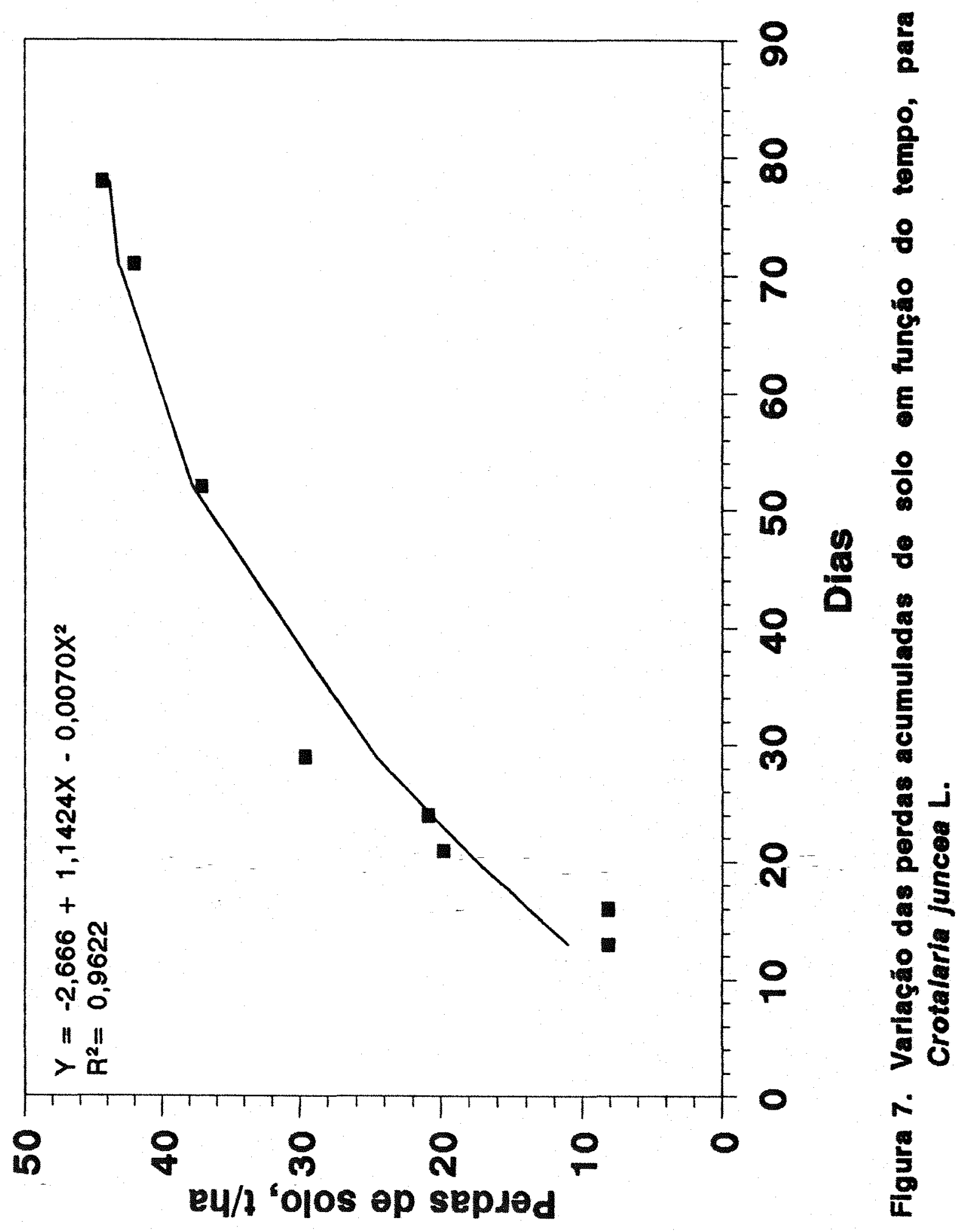




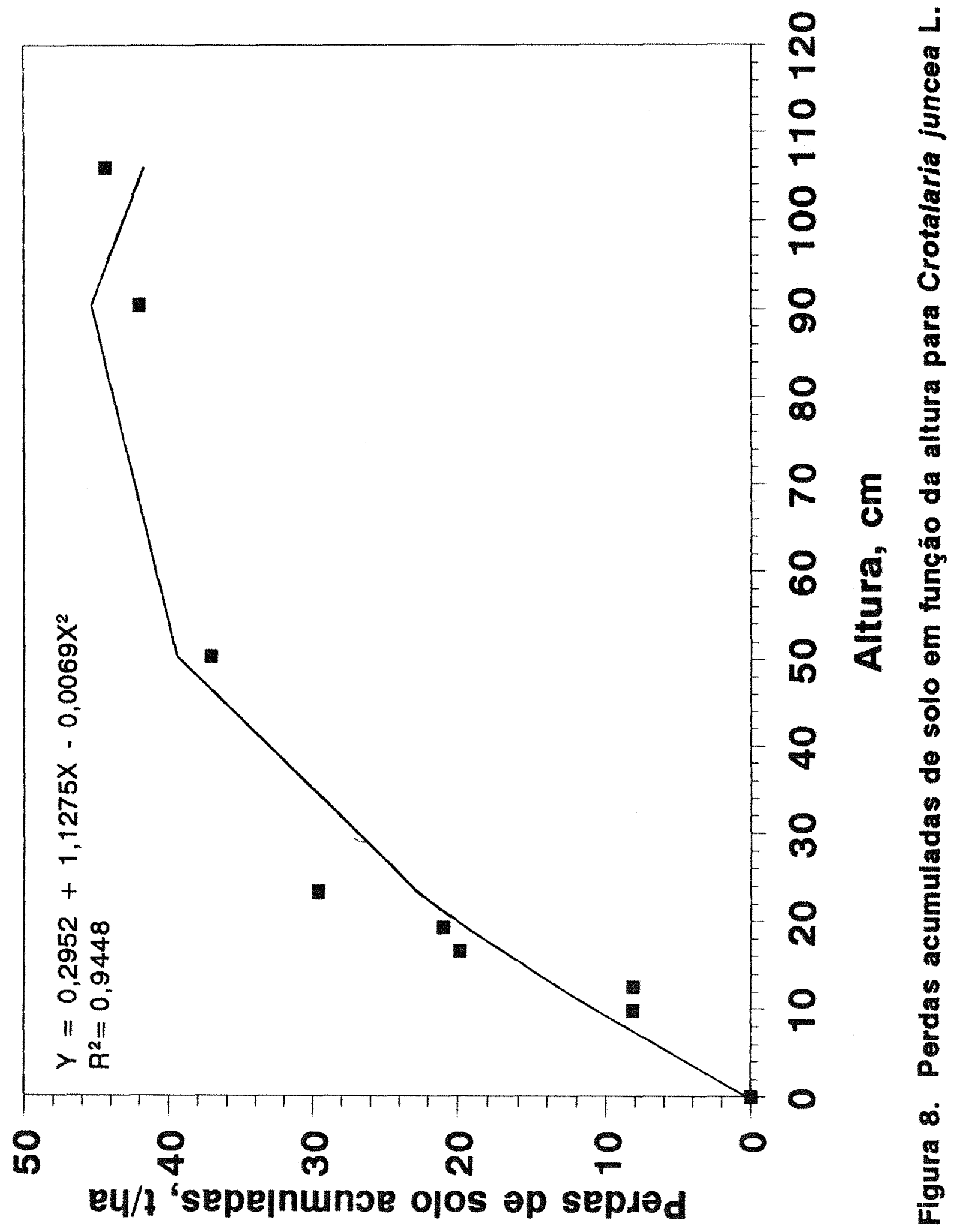


Para a avaliação do desenvolvimento da crotalaria juncea para fins de adubação verde três estádios são indicados: da semeadura a 30 dias, de 30 a 60 dias e de 60 a 90 ou 120 dias.

Através desses dados a avaliação da razão de perdas de solo para três leguminosas quando ut ilizadas para adubação verde em rotação foi estabelecida.

4.2. Avaliação da razão de perdas de solo para três leguminosas

A Tabela 4 apresenta os valores de perdas de solo para o talhão descoberto, como também para os talhões com leguminosas, para vários estádios da cultura. A partir desses resultados foram calculados os valores de razão de perdas de solo para os estádios considerados, para as três leguminosas, relacionando as perdas de solo do estádio de cada cultura com as perdas de solo no mesmo periodo, para o talhão descoberto.

A Tabela 5 apresenta os dados de perdas de solo para os periodos de $0-30,0-60,0-90$ e $0-120$ dias, considerando um estádio apenas para as culturas.

A Figura 9 mostra os valores de razão de perdas de solo para as três leguminosas estudadas nos 4 estádios definidos. A Figura 10 mostra os valores de RPS para 4 períodos do ciclo das espécies. 
Tabela 4. Perdas de solo para três leguminosas e solo descoberto, em quatro estádios da cultura

$73 / 74 \quad 74 / 75 \quad 75 / 76 \quad 76 / 77 \quad 77 / 78 \quad 78 / 79$ Soma Média

t/ha

0-30 dias

$\begin{array}{lllllllll}\text { Descoberto } & 4.20 & 8.02 & 21.27 & 0.20 & 0.00 & 12.02 & 45.71 & 7.62 \\ \text { Crotalária } & 4.63 & 0.82 & 4.36 & 0.04 & 0.00 & 4.08 & 13.93 & 2.32 \\ \text { Mucuna } & 2.16 & 1.01 & 5.18 & 0.04 & 0.00 & 4.38 & 12.77 & 2.13 \\ \text { Labelabe } & 8.25 & 0.00 & 4.36 & 0.04 & 0.00 & 6.24 & 18.89 & 3.78\end{array}$

30-60 dias

$\begin{array}{lllllllll}\text { Descoberto } & 0.03 & 14.07 & 17.55 & 13.23 & 3.60 & 5.25 & 53.73 & 8.96\end{array}$

$\begin{array}{lllllllll}\text { Crotalária } & 0.85 & 1.20 & 4.90 & 9.93 & 1.83 & 3.98 & 22.69 & 3.78\end{array}$

$\begin{array}{lllllllll}\text { Mucuna } & 0.13 & 1.73 & 4.43 & 6.43 & 1.78 & 5.36 & 19.86 & 3.31\end{array}$

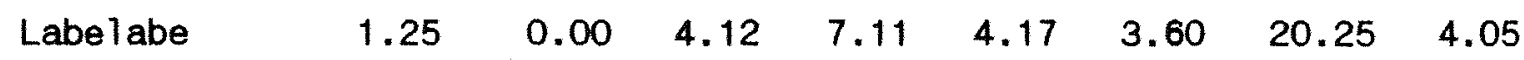

60-90 dias

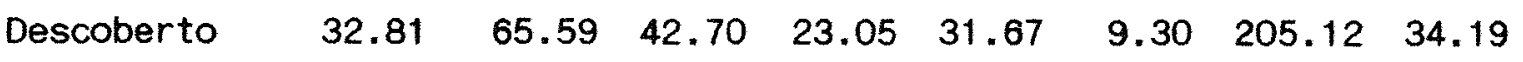

$\begin{array}{lllllllll}\text { Crotalária } & 13.98 & 2.55 & 5.61 & 12.50 & 17.93 & 1.52 & 54.09 & 9.02\end{array}$

$\begin{array}{lllllllll}\text { Mucuna } & 5.26 & 6.20 & 4.09 & 2.28 & 17.23 & 0.55 & 35.61 & 5.94\end{array}$

$\begin{array}{lllllllll}\text { Labelabe } & 12.71 & 0.00 & 6.83 & 6.55 & 18.20 & 1.25 & 45.54 & 9.11\end{array}$

60-120 dias

$\begin{array}{lllllllll}\text { Descoberto } & 97.67 & 105.61 & 65.93 & 68.10 & 35.16 & 50.02 & 422.49 & 70.42\end{array}$

$\begin{array}{lllllllll}\text { Crotalária } & 33.84 & 3.60 & 7.24 & 28.86 & 19.22 & 8.01 & 100.77 & 16.80\end{array}$

$\begin{array}{lllllllll}\text { Mucuna } & 7.01 & 6.20 & 4.42 & 2.60 & 17.75 & 0.62 & 38.60 & 6.43\end{array}$

$\begin{array}{lllllllll}\text { Labelabe } & 23.74 & 0.00 & 7.92 & 14.07 & 18.81 & 2.20 & 66.74 & 13.35\end{array}$ 
Tabela 5. Perdas de solo para três leguminosas e solo descoberto, em quatro períodos da cultura

\begin{tabular}{lrrrrrrrr}
\hline & $73 / 74$ & $74 / 75$ & $75 / 76$ & $76 / 77$ & $77 / 78$ & $78 / 79$ & Soma & Média \\
\hline & - & & & & & t/ha & & \\
\hline
\end{tabular}




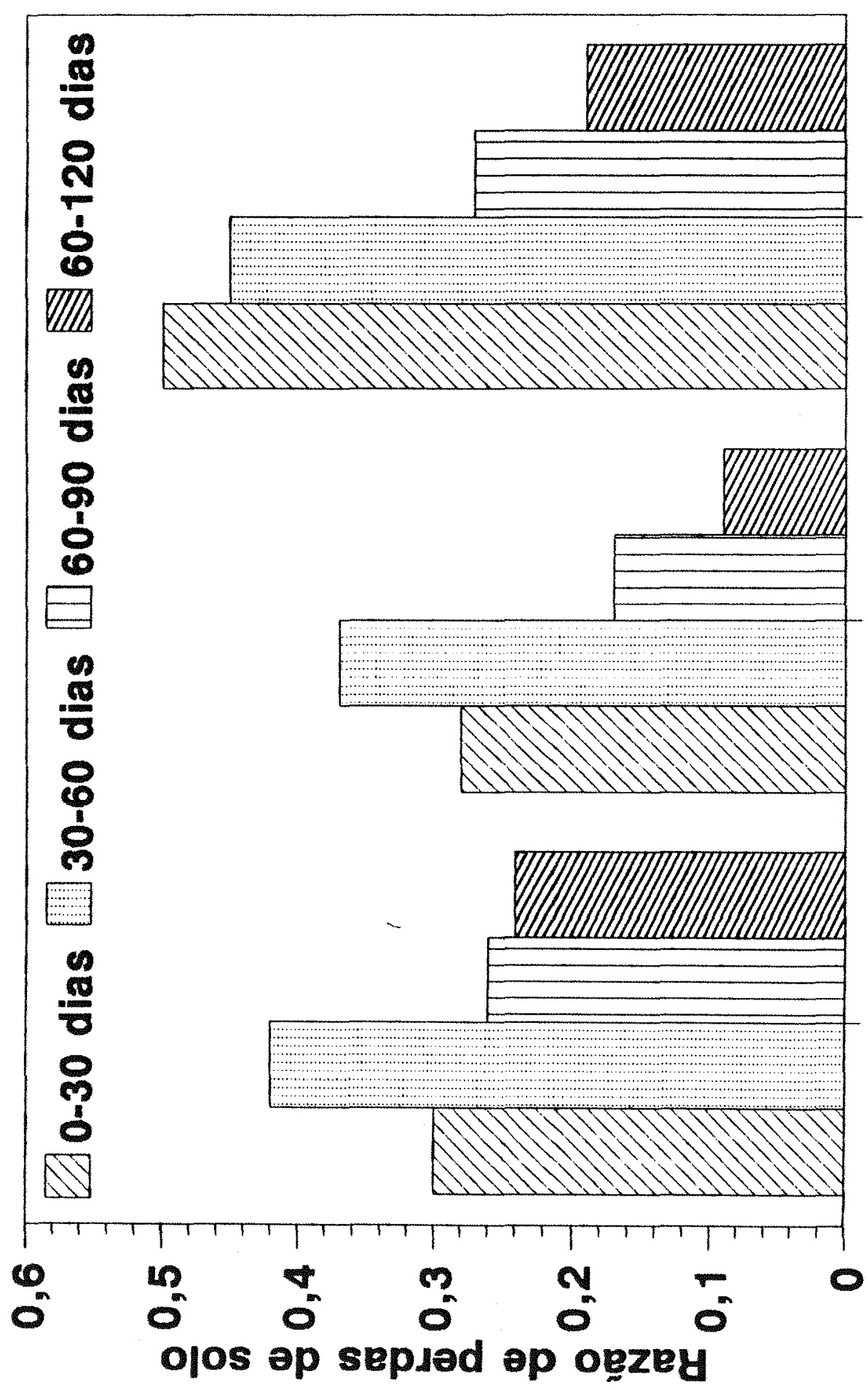

9

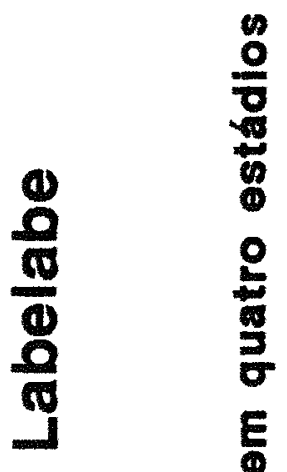

$+2$

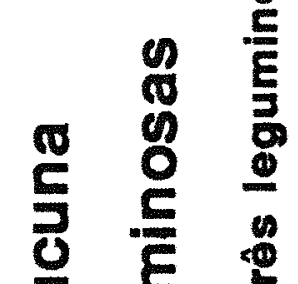

35

0

응

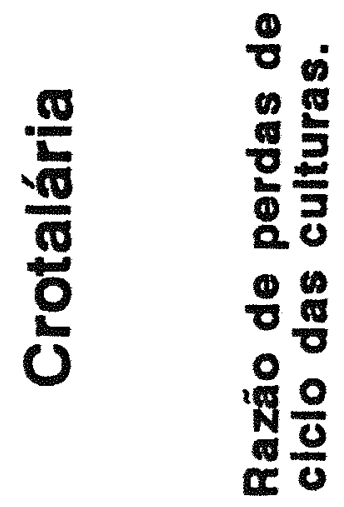

$\frac{0}{5}$ 


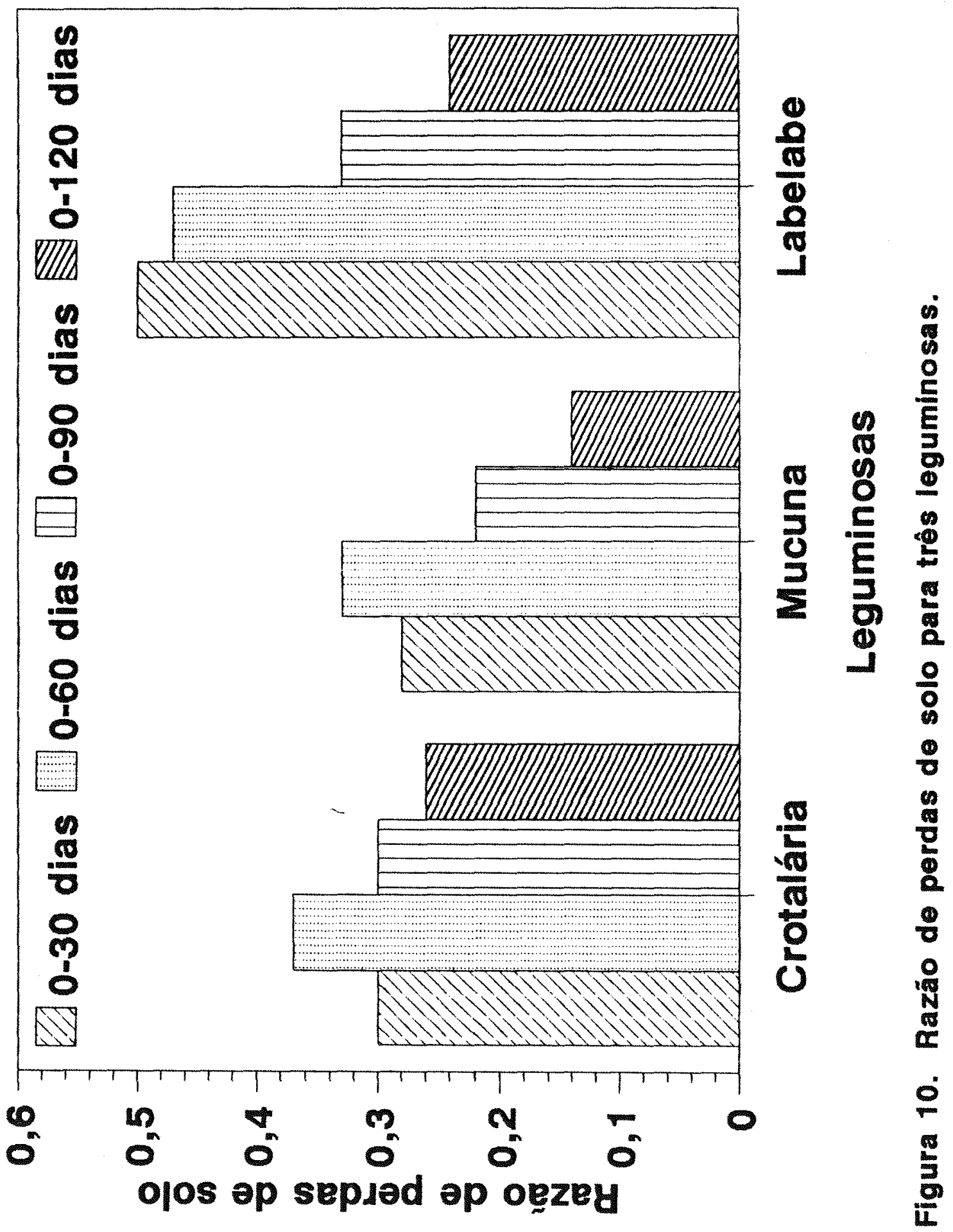


Destacam-se os valores de RPS para 60 dias, acumulados ou não. Os valores mostram-se maiores que os obtidos para o primeiro período, ao contrário do esperado, visto que no segundo periodo existe um maior desenvolvimento da cultura expresso, por exemplo, em maiores percentuais de cobertura do solo.

E importante notar, no entanto, que esses resultados são influenciados pelas perdas de solo observadas no primeiro ano agrícola considerado $(1973 / 74)$, quando as perdas do solo para o talhão descoberto foram menores devido ao efeito residual do manejo anterior.

WISCHMEIER \& SMITH (1978) e MUTCHLER et a1. (1982), entre outros, destacam a importância de fatores como o uso e manejo do solo em anos anteriores, assim como resíduos culturais incorporados, nas perdas do solo. Isso poderia explicar a pequena perda do solo no talhão descoberto no primeiro ano, mas esse valor destacadamente menor se concentrou no período 'até 60 dias, não sendo observado nos outros períodos.

Os números resultantes das RPS mostram, de qualquer forma, a presença de uma ação mais efetiva das leguminosas a partir de 60 dias, o que pode ser notado através da acentuada queda nos valores de RPS. Assim, observando-se as relações entre perdas para os estádios, a diminuição dos valores médios chega a cerca de $40 \%$ para a crotalária e o labelabe, e mais de 50\% para a mucuna-preta. Esse comportamento é notado, inclusive, para quase todos os anos em que foram 
avaliadas as perdas do solo, constituindo-se em uma tendência geral.

A partir do periodo inicial de 60 dias até 0 estádio de florescimento das plantas, as RPS permanecem em queda acentuada e contínua. Isso pode ser notado pela análise dos dados obtidos nos períodos 60-90 e 60-120 dias bastante menores que os do período anterior.

WISCHMEIER \& SMITH (1965) estabeleceram um só estádio para o adubo verde, o qual era utilizado em rotação de culturas.

A comparação dos períodos acumulados mostra uma variação mais discreta, obviamente pela inclusão, nos valores finais, das perdas de solo verificadas desde o inicio do ciclo. De qualquer modo, também é constatada uma queda nos resultados em termos de RPS conforme avança o ciclo da cultura, com um aumento no período 0-60 dias para crotalária e mucuna-preta, como já foi comentado anteriormente.

Os resultados obtidos permitem algumas observações. Avaliando as vantagens da cobertura vegetal, ALENCAR (1950) destacou principalmente a proteção contra o impacto da chuva exercida pela cobertura e a melhoria das condições físicas, químicas e biológicas do solo. Desse modo, o segundo aspecto irá influenciar em propriedades como a permeabilidade e a infiltração da água no solo.

MEDINA \& LEITE (1985), estudando o efeito de várias plantas de cobertura em consorciação com seringueira, em relação a propriedades físicas do solo, encontraram altas 
taxas de infiltração para solo sob a cultura de uma leguminosa, o kudzu (Pueraria phaseoloides Benth). Essa propriedade, como mostram os autores, está associada a caracteristicas como alta porosidade total e baixos valores de densidade global do solo. DERPSH et al. (1986) conseguiram maiores valores de infiltração, implicando em menor "enxurrada", para sistemas de manejo de rotação de culturas com leguminosa.

o efeito nas condições do solo, no entanto, é conseguido para sistemas de manejo a longo prazo. Assim, para explicar a diminuição relativa das perdas do solo, expressas em RPS, ao longo do ciclo da cultura, a cobertura do solo se destaca como o fator de maior influência. Isso pode ser constatado, inclusive, ao se observar que a ação das leguminosas na proteção do solo passou a ser sentida após um certo tempo decorrido da instalação das culturas. Este periodo, segundo os resultados obtidos, de até 60 dias após a semeadura está assim relacionado ao desenvolvimento das plantas e maior capacidade de cobertura do solo.

FOURNIER (1967) avaliou a capacidade de proteção contra a erosão a partir de alguns valores de cobertura do solo com gramíneas destinadas a pastagem. O autor obtém, também, dados indicando que a crotalária e o labelabe, quando comparadas a outras espécies (graminea do gênero Penissetum e leguminosa do género Pueraria, respectivamente), apresentam um desenvolvimento vegetativo mais lento, ocasionando maiores perdas de solo especialmente no início do ciclo da cultura. 
ADAMS Jr. (1979) também considerou a necessidade do rápido estabelecimento das plantas especialmente em regiós com chuvas de alto potencial erosivo, para propiciar maior proteção ao solo, em trabalho que analisa alternativas para a proteção de áreas declivosas.

A duração do período de estabelecimento de plantas, até o momento em que adquirem maior capacidade de cobertura do solo, é variável de acordo com uma série de fatores. Aspectos como a espécie de planta, suas características, as condições climáticas e do solo irão ter influência.

Em relação a comparação entre as espécies de leguminosas avaliadas, a mucuna-preta apresentou, desde o estádio inicial de desenvolvimento, a melhor proteção do solo contra a erosão. No estádio inicial a crotalária também apresenta comportamento favorável, e ambas superaram em muito a proteção oferecida pelo labelabe. A Figura 9 mostra que o labelabe oferece pouca proteção ao solo até aos 60 dias em relação a mucuna e a crotalária. Após 60 dias a mucuna é a que melhor proteção oferece ao solo, apresentando o menor valor de razão de perdas.

No infcio do ciclo a crotalária a mucuna-preta, apresentaram valores de RPS muito próximos $(0,30$ e 0,28$)$, caracterizando entre as espécies uma protecão do solo semelhante, superior ao labelabe (RPS $=0,50)$. Após o período de 60 dias, a mucuna-preta apresenta uma proteção acentuadamente melhor em relação a outras espécies, chegando a uma RPS média de 0,09 para 60-120 dias. O labelabe, também 
apresentando uma melhora significativa na proteção contra a erosão, passa a ter valores de RPS semelhantes a crotalária (respectivamente 0,27 e 0,26 para 60-90 dias, e 0,19 e 0,24, para $60-120$ dias).

Estes resultados apresentam ligação estreita com as características das espécies. WUTKE (1993), por exemplo, destacou o grande vigor e a capacidade de desenvolvimento da mucuna-preta, o que pode explicar a maior proteção exercida desde o início do ciclo. o autor também caracteriza a crotalária como uma espécie de rápido desenvolvimento vegetativo, justificando a proteção sat isfatoria exercida no período inicial.

MIYASAKA (1984) classificou a crotalária como de características de crescimento diferentes das de mucuna-preta e labelabe. Assim, a primeira apresenta características de maior altura de planta e porte ereto, com pequena expansão do dosse1, enquanto as outras apresentam menor altura e grande expansão latera1. O autor também caracterizou o labelabe como uma leguminosa de forma semelhante a mucuna-preta, porém com crescimento menos agressivo em relaça a esta. Isso normalmente se reflete em menor cobertura e proteça do solo contra a erosão, especialmente no início do ciclo. NAKAGAVA (1984), também estudando o comportamento do guandu e labelabe quanto a produção de massa verde e sementes, atestou a menor produção do segundo.

WISCHMEIER \& SMITH (1978), ao analisarem a cobertura vegetal como fator de proteção contra a erosão, 
mostraram a maior eficiência de plantas de menor altura. STOCKING (1988) citou o porte alto de plantas como uma desvantagem na proteção contra a erosão. Esta af exposto um aspecto em que a mucuna e o labe-labe se sobressaem em relação a crotalária.

Além disso, o tipo de crescimento também tem influência marcante, com a maior expansão lateral do dossel vegetativo resultando em maiores percentuais de cobertura do solo.

Os resultados permitem assim algumas considerações sobre o comportamento das espécies testadas. A mucuna-preta, de rápido desenvolvimento e características favoráveis de crescimento, apresentou desde o início do ciclo um razoável potencial de proteção contra erosão, acentuando-se bastante com o desenvolvimento da planta. o labelabe, de características semelhantes a mucuna em relação a morfologia da planta, porém com estabelecimento mais lento, apresenta grande aumento no potencial de controle da erosão no final do ciclo. A crotalária, com seu desenvolvimento relativamente mais rápido proporciona uma proteção inicial, mas a evolução ao longo do ciclo não é tão significativa quanto à das outras espécies.

WISCHMEIER \& SMITH (1965) dividiram o ciclo de algumas culturas anuais em estádios semelhantes aos escolhidos no presente trabalho. Os resultados obtidos para culturas como milho, sorgo, algodão e culturas de pequeno porte ("small grain") são muito variáveis em relação aos 
valores de RPS, sendo influenciados grandemente pelo sistema de rotação de culturas estabelecido, o tipo de preparo do solo e o rendimento da cultura avaliada e das culturas precedentes.

Pode-se afirmar, no entanto, que para a situação de preparo convencional do solo e de plantio contínuo essas culturas tiveram comportamento semelhante ao labelabe no inicio do ciclo, não apresentando a mesma evolução em relação ao aumento da proteção do solo no fim do ciclo.

\section{BERTONI \& LOMBARDI NETO (1990), analisando as} mesmas culturas, apresentaram valores muito inferiores de RPS para o milho, superando os valores obtidos para as leguminosas estudadas. Em reląão a algodão e soja, as RPS apresentaram valores semelhantes aos outros dados citados.

Esses trabalhos mostraram, de forma bastante acentuada, a influência dos sistemas de preparo do solo e rotaça de culturas nos valores de RPS. Assim, como as leguminosas testadas foram instaladas em simulação de preparo convencional, e com pousio no inverno, pode-se inferir que essas mesmas espécies, conduzidas em sistemas de rotação de culturas e preparo do solo de carater conservacionista, poderão apresentar resultados de RPS bem menores que os observados. Também práticas como a adubação mineral que não foi utilizada durante a condução do experimento, podem resultar em um desenvolvimento maior e mais rápido das espécies, resultando em maior proteção contra a erosão. 


\section{CONCLUSŌES}

a) As leguminosas estudadas, utilizadas como adubacão verde, apresentam diferentes capacidades de proteçăo do solo.

b) A proteção do solo se torna mais efetiva a partir de 60 dias apos o plantio.

c) Algumas diferencas podem ser notadas entre as leguminosas estudadas, ao longo dos seus ciclos, em relação a proteção contra a erosão. Essas diferenças são devidas, principalmente, a evolução e caracteristicas de crescimento apresentadas pelas espécie.

d) A mucuna-preta apresenta, entre as espécies estudadas, a melhor proteçăo do solo contra a erosão, com a crotalária apresentando no inicio do ciclo uma eficiência semelhante. A partir da metade do ciclo vegetativo, a maior eficiencia da mucuna-preta se acentua; e o labelabe, com uma evolução destacada na capacidade de protecão, passa a apresentar uma ação similar a crotalária. 
e) Entre os períodos considerados, de $0-30$ a $0-120$ dias apos plantio, a redução de RPS foi de 50\% para a mucuna-preta $(0,28$ a 0,14$), 52 \%$ para o labelabe $(0,50$ a 0,24$)$ e $13 \%$ para a crotalária $(0,30$ a 0,26$)$. Em relação aos estádios da cultura de $0-30$ a 60-120 dias após o plantio, a mucunapreta apresentou redução nos valores de RPS de cerca de $66 \%(0,28$ a 0,09$)$, o labelabe de $62 \%(0,50$ a 0,19$)$ e a crotalária de $25 \%(0,30$ a 0,24$)$.

f) Com vistas a maior precisão dos resultados, novas pesquisas deverão ser conduzidas para avaliacão de espécies de adubos verdes de verão na proteção contra erosão, bem como na avaliação de métodos de determinação de parâmetros como a cobertura do solo proporcionada por estas espécies durante o ciclo no campo. 


\section{REFERENCIAS BIBLIOGRAFICAS}

ADAMS Jr., T.; KAY, B.L.; COPPOCK, R. \& WILDMAN, W.E. Erosion control on bare slopes around your home. Berkeley, CA, University of California, Division of Agricultural Sciences, 1979. $7 p$.

ALENCAR, F.M.A. Conservação do solo e revestimento vegetal. superintendência dos serviços do Café, secretaria da Agricultura, São Paulo, 1950. 16p. (Boletim 278)

AMADO, T.J.C. Determinação da velocidade e da percentagem de cobertura do solo por adubos verdes através do método da largura do dossel vegetativo. In: CONGRESSO BRASILEIRO DE CIENCIA DO SOLO, 21., Londrina, 1990. Anais. Sociedade Brasileira de Ciência do Solo, 1991.

BAVER, L.D. Soil Physics, New York, John wiley \& Sons, Inc. 1948. $398 p$. 
BENNETT, H.H. Elements of soil conservation. MC Grall Hill Book Company, New York, 1947. p.12-15.

BERTONI, J. Sistemas coletores para determinação de perdas por erosão. Bragantia, Campinas, 9:147-155, 1949.

BERTONI, J. Determinação da velocidade de infiltração da água no solo por meio de diagramas de pluviógrafos e linigrafos. Bragantia, Campinas, 18: 169-197, 1959.

BERTONI, J. \& LOMBARDI NETO, F. Conservação do solo, São Paulo, fcone Editora, 1990. 355p.

BERTONI, J.; PASTANA, F.I.; LOMBARDI NETO, F. \& BENATTI Jr., R. Conclusões gerais das pesquisas sobre conservação do solo no Instituto Agronómico, Campinas, Instituto Agronômico, 1972. 56p. (Circular, 20)

BULIZANI, E.A. \& BRAGA, N.R. Potencialidades para o uso de leguminosas como cobertura vegetal de inverno no Estado de São Paulo. In: Atualização em plantio direto, Coords. FANCELLI, A.L.; TORRADO, P.V. e MACHADO, J. Campinas, Fundação Cargi11, 1985. p.223-235.

CHISCI, G. \& ZANCHI, C. The influence of different tillage systems and different crops on soil losses on Hilly siltyclayey soil. In: Soil Conservation: Problems and 
perspectives. R.P. Morgan (ed.). John Wiley and Sons Bedford, 1981. p.211-214.

DECHEN, S.C.F.; LOMBARDI NETO, F.; CASTRO, O.M. de. Gramíneas e leguminosas e seus restos culturais no controle da erosão em latossolo roxo. Revista Brasileira de Ciência do Solo. Campinas, 5(2): 133-137, 1981 .

DENARDIM, J.E. Erodibilidade do solo estimada por meio de parametros físicos e químicos. Piracicaba, ESALQ/USP, 1990. 110p. (Tese de Doutorado)

EL-SWAIFY, S.A.; LO, A.; JOY, R.; SHINSHIRO, L. \& YOST, R.S. Achieving conservation-effectiveness in the tropics using legume intercrops. Soil Technology, cremlingen, $w$. Germany, 1: 1-12, 1988 .

ELWELL, H.A. \& GARDNER, S. Comparasion of two technques for measuring percent crop canopy cover on row crops in erosion research programmes. Rodhesia, Causeway, Salisbury, Department of Conservation and Extension, 1976. 250p. (Research Bulletin, 19)

ELWELL, H.A. \& STOCKING, M.A. Vegetal cover to estimate soil erosion hazard in Rhodesia. Geoderma, Amsterdam, 15: 6170. 1976 . 
ELWELL, H.A. \& WENDELAAR, F.E. To iniciate a vegetal cover data bank for soil loss estimation, Rodésia Causeway, Salisbury, Department of Conservation and Extensión, 1977. 42p. (Research Bulletin, 23)

FOURNEIR, F. Research on soil erosion and soil conservation in Africa. African Soils. Inter-African Bureau for Soils, $12(1): 53-96,1967$.

GILLEY, J.E.; FINKNER, S.C. ; SPOMER, R.G. \& MIELKE,L.N. Runoff and erosion as affected by corn residue: Part 1 Total losses. Transaction of the ASAE, Saint Joseph, 29: 157-160. 1986

KRAMER, L.A. \& ALBERTS, E.E. C factors for corn under changing management. Transactions of the ASAE, St. Joseph, $29(6): 1590-1596.1986$.

LAFLEN, J.M.; FOSTER, G.R. \& ONSTAD, C.A. Simulation of individual storm soil loss for modeling the impact of soil erosion on crop productivity. In: EL SWAIFY, S.A., MOLDENHAUER, W.C. \& LO, A. (Ed.). Soit Erosion and Conservation, Ankeny, Soil Conservation Society of America. 1985. p.285-295.

LOMBARDI NETO, F. Rainfall erosivity - its distribution and relationship with soil loss at Campinas, Brazil. West 
Lafayette, 1977. 53p. Dissertação (Mestrado) Purdue University, 1977

LOMBARDI NETO, F.; DE MARIA, I.C.; CASTRO, O.M. de; DECHEN, S.C.F. \& VIEIRA, S.R. Efeito da quantidade de resíduos culturais de milho nas perdas de solo e água. Revista Brasileira de Ciência do Solo, Campinas, 12: 71-75, 1988.

LOPES, P.R.C.; COGO, N.P. \& LEVIEN, R. Eficácia relativa de tipos e quantidades de residuos culturais espalhados uniformemente sobre o solo na redução da erosão hídrica. Revista Brasileira de Ciência do Solo, Campinas, 11: 71-75, 1987 .

MANNERING, J.V. \& MEYER, L.D. The effect of various rates of surface mulch on infiltration and erosion. Soil Science Society of America Proceedings, Madison, 27(1): 84-86, 1963.

MASCARENHAS, H.A.A.; MIYASAKA, S.; ALMEIDA, L.D. de; FREIRE, E.S. \& ALCOVER, M. Adubação verde do feijoeiro "da seca" com ervilha de vaca. Bragantia, 26: 37-45. 1987.

MEDINA, B.F. \& LEITE, J.A. Influência de três sistemas de manejo e duas coberturas vegetais na infiltração de água em um latossolo amarelo em Manaus ( $A M$ ). Pesquisa Agropecuária Brasileira, Brasilia, 20(11): 1323-1331, 1985. 
MIYASAKA, S. Histórico de estudos de adubação verde, leguminosas viáveis e suas características. In: Adubação verde no Brasi1, Fundação Cargi11, Campinas, 1984. p.64124 .

MORGAN, R.P.C. Establishment of plant cover parameters for modelling splash detachment. In: EL-SWAIFY, S.A.; MOLDENHAUER, W.C. \& LO, A. (Ed.). Soil conservation and erosion. Soil Conservation Society of America, Ankeny, 1985. p.377-383.

MUTCHLER, C.K.; MURPHREE, C.E.; MCGREGOR, K.C. Subfactor method for computing $\mathrm{C}$ factors for continuous cotton. Transactions of the ASAE, Saint Joseph, 25(2): 327-332, 1982

NAKAGAVA, J. Estudos desenvolvidos com as culturas do guandu e 1ab-lab em condições de São Manuel (SP). In: Adubação verde no Brasi1, Fundação Cargi11. Campinas, 1984. p.173176.

PEETEN, H. O controle da erosão em 200 mil ha cultivados na região dos campos gerais do Paraná, pelo sistema de plantio direto. In: Plantio direto no Brasil, Coord. TORRADO, P.V. e Aloisi, R.R., Fundação Cargi11, Campinas. 1984. p.7992. 
SALGADO, A.L.B.; BULISANI, E.A.; BRAGA, N.R. \& MIRANDA, M.A.C. de. Crotalaria juncea L. In: Instruções agricolas para o Estado de São Paulo. Campinas, Instituto Agronómíco, 1990, p.84-85. (Boletim 200)

SINGER, M.J. \& BLACKARD, J. Effect of mulching on sediment in runoff from simulated rainfall. Soil science Society of American Journal, Madison, 42: 481-486, 1978.

SINGER, M.J.; MATSUDA, Y. \& BLACKARD, J. Effect of mulch rate on soil loss by raindrop splash. Soil science society of American Journa1, Madison, 45(1): 107-110, 1981.

STOCKING, M.A. Assessing vegetative cover and management effect. Soil erosion research methods. Ed. by R. LAL. Soil and Water Conservation Society, Iowa, 1988. p.163167.

VEIGA, A.A.; BULISANI, E.A.; MIYASAKA, S.; ALMEIDA, L.D. \& VAN RAIJ, B. Efeito da incorporação ao solo de massa vegetal da crotalária juncea, calagem e adubação com nitrogénio e fósforo na produção do feijoeiro. Instituto Agronómico, Campinas, 1977. 18p. (Boletim técnico 48)

WISCHMEIER, W.H. \& SMITH, D.D. A universal soil loss equation to guide conservation farm planing. International congress Soil Science, $7^{\text {th }}$ Madison, Wisconsin, 1960. p.418-425. 
WISCHMEIER, W.H. \& SMITH, D.D. Predicting rainfall erosion 1osses. A guide to conservation planning. Agriculture Handbook no 537. United States Department of Agriculture, Washington D.C. 1978. 58p.

WISCHMEIER, W.H. \& SMITH, D.D. Predicting rainfa11-erosion losses from cropland East of the Rocky Mountans: guide for selections of practices for soil and water conservation. Agricultural Research Service, US Department of Agriculture, Washington, 1965. 47p. (Agr. Handbook 282)

WUTKE, E.B. Adubação verde: manejo da fitomassa e espécies utilizadas no Estado de São Paulo. In: I Curso de adubação verde do Instituto Agronómico de Campinas, 1993. p.17-29. (Documento no 35 )

ZULLo, J.R. \& ARRUDA, F.B. Programa computacional de ajuste de equações em dadós experimentais. Instituto Agronómico, Campinas, 1986. 23p. (Bot. téc. no 113) 